\title{
Systematic integration of LCA in process systems design: Application to combined fuel and electricity production from lignocellulosic biomass
}

Laboratory for Industrial Energy Systems, Ecole Polytechnique Fédérale de Lausanne CH - 1015 Lausanne, Switzerland

\author{
Léda Gerber, Martin Gassner, François Maréchal
}

Computers and Chemical Engineering (2011), doi:10.1016/j.compchemeng.2010.11.012

\begin{abstract}
This paper presents a methodology to integrate life cycle assessment (LCA)in thermoeconomic models used for the optimal conceptual design of energy conversion systems. It is illustrated by an application to a thermo-economic model developed for the multi-objective optimization of combined synthetic natural gas (SNG) and electricity production from lignocellulosic biomass. The life cycle inventory (LCI) is written as a function of the parameters of the thermo-economic model. In this way, the obtained environmental indicators from the life cycle impact assessment (LCIA) are calculated as a function of the decision variables of process design. The LCIA results obtained with the developed methodology are compared with the results obtained by a conventional LCA of the same process. Then, a multi-objective environomic (i.e. thermodynamic, economic, environmental) optimization of the process superstructure is performed. The results highlight the important effects of process configuration, integration, efficiency and scale on the environmental impacts.
\end{abstract}

Keywords: Process systems design, Biofuels, Synthetic Natural Gas, Life Cycle Assessment, Optimization

\section{Nomenclature}

$\dot{m} \quad$ mass flow rate

$A_{j} \quad$ functional parameter related to size

E emission of the LCI

F weighting factor for impact calculation

I impact

$i \quad$ subscript to identify an elementary flow

$j \quad$ subscript to identify a LCI element

$k \quad$ exponent

$M_{j}^{F U}$ amount of the LCI element $j$ per functional unit

$r_{\text {operation }}$ yearly operation percentage of installation

$t_{l i f e}$ installation lifetime 
$x_{d} \quad$ decision variables of the optimization problem

c correction factor

CFB Circulating Fluidized Bed

CHP Combined Heat and Power

FICFB Fast Internally Circulating Fluidized Bed

FU Functional Unit

LCA Life Cycle Assessment

LCI Life Cycle Inventory

LCIA Life Cycle Impact Assessment

$\mathrm{MW}_{t h} \mathrm{MW}$ of wood based on dry matter lower heating value

NG Fossil Natural Gas

pFICFB pressurized Fast Internally Circulating Fluidized Bed

RME Rape Methyl Ester

SNG Synthetic Natural Gas

\section{Introduction}

Environmental impacts of emerging technologies such as the production of fuels from biomass have become an important concern. To assess these impacts, life cycle assessment (LCA) is a widely used and well-established method, standardized in ISO (2006a,b). However, for such processes, conventional LCAs are generally based on an average technology at lab- or pilot-scale that are extrapolated to large scale. Typically, this is done by using linear scaling models and literature data that are not necessarily consistent since these are collected from different sources. Examples of such an approach are the environmental impact assessments for biofuels of Felder and Dones (2007) or Zah et al. (2007) in the Swiss context, or the study of von Blottnitz and Curran (2007) on the international level.

With this classical approach, changes in process configuration or design conditions, effects of process integration, future installation size and technology evolution are not considered and cannot be evaluated. At the most, a few scenarios based on average technologies may be discussed. It is therefore difficult for engineers to integrate the LCA at the conceptual process design stage to target not only the economic performances but also simultaneously the environmental impacts.

Some studies on the use of LCA in a process design context have already been conducted. Keoleian (2003) presents general guidelines to apply the LCA in a product design context. However, he does not provide indications on how to specifically use the LCA in a computer aided process design environment and with optimization techniques. Later, Stefanis et al. (1995) proposed a methodology to integrate LCA in the design of chemical process systems, considering cumulated environmental impacts, and integrated these environmental criteria in the minimization of operating costs. The following studies of Kniel et al. (1996), Azapagic and Clift (1999) and Alexander et al. (2000) deal with the use of LCA in a multi-objective optimization framework to calculate the trade-offs between economic and environmental objectives. Hugo and Pistikopoulos (2005) go further by introducing a strategy to synthesize supply chains, considering both costs and cumulated impacts from life cycle impact assessment in a multi-objective optimization using mixed integer linear programming (MILP) techniques. Guillén-Gosálbez et al. (2008) propose as 
well a similar approach to directly extract the optimal flowsheet configurations from the process superstructure for the design of chemical processes in the multi-objective optimization, but using mixed integer non-linear programming (MINLP). Extending this approach, Guillén-Gosálbez and Grossmann (2010) present a strategy for the multi-objective optimization of chemical supply chains, including uncertainties in the environmental impact model. More specifically in the field of renewable resources, Alvarado-Morales et al. (2009) detail a systematic methodology for the sustainable design of biorefineries that integrates environmental criteria. However, most of the examples of application presented in these works come from the field of product manufacture, and therefore do not consider the specificities of energy systems design, such as the production of multiple energy services or the successive technology generations in the case of an emerging technology. Specifically in the field of energy systems, a study conducted by Papandreou and Shang (2008) concerned the use of the LCA in a multi-objective optimization framework for utility systems design, but focused mainly on the on-site emissions, and does not consider life cycle aspects. This issue has been addressed by Martinez and Eliceche (2009), who propose a strategy for the minimization of life cycle $\mathrm{CO}_{2}$ emissions in power plants, but do not include an economic criterion as an optimization objective. Gebreslassie et al. (2009) proceed in the integration of LCA in the process design and optimization of energy systems, by introducing, for absorption-cooling systems, to link the life cycle inventory (LCI) to the quantities of steam and electricity that are calculated by their mass and energy flow model. However, none of the three studies above consider the use of process integration techniques. Luterbacher et al. (2009) used the LCA in conjunction with energy integration techniques for the environmental evaluation of synthetic natural gas (SNG) production by hydrothermal gasification. However, they did not develop a specific methodology to express directly the LCA as a function of the thermo-economic model, and no process optimization was performed. Extending the approach of Li et al. (2006), Bernier et al. (2010) used LCA in a multi-objective optimization framework to calculate the trade-off between the levelized cost of electricity and the life cycle global warming potential for a natural gas combined cycle power plant with carbon dioxide capture. The method was targeting a single energy service and the results show that when fossil fuel resources are used, increasing the efficiency is equivalent to minimize the environmental impact. They also demonstrate the use of the LCA to evaluate the impact of a $\mathrm{CO}_{2}$ tax.

From this literature review, it appears that several strategies have been developed for the integration of LCA in frameworks for the process design and optimization, in particular in the field of chemical process design. Though it is generally agreed that the LCI flows have to be linked to the flowsheet, no specific methodology has yet been reported for identifying these flows according to the LCA system boundaries and for establishing the mathematical formulations that allow for linking them to process superstructures or flowsheets. Moreover, Grossmann and Guillén-Gosálbez (2010) have recently observed that one of the major remaining limitations of the application of LCA methodology to process systems design is the lack of a systematic method for generating and identifying process alternatives that minimize the life cycle impact while still yielding good economic performance. The present work addresses these issues and proposes a systematic approach for integrating LCA in process systems design using multi-objective optimisation, which allows for simultaneously considering the influence of the process design and its integration on the thermodynamic, economic and environmental life-cycle performance at the early stage of conceptual process synthesis. In particular, the paper presents a systematic methodology to integrate LCA indicators in an existing computer aided process engineering platform for the optimal thermo-economic design of polygeneration systems for (renewable) energy services. The method is illustrated here using a thermo-economic model developed for the process design of thermochemical cogeneration of SNG and power from lignocellulosic biomass (Gassner and Maréchal, 2009b), and has also proven useful for the production of liquid fuels (Tock et al., 2010a,b). 


\section{Methodology}

The thermo-economic design approach described in Gassner and Maréchal (2009a) is based on a computational platform that combines the energy flow models of the process unit operations and process integration techniques to model the interactions between unit operations. In a first time, the energy flow model calculates the thermochemical transformations in the process units for a specific configuration and operating conditions. The resulting mass and energy flows are then used to generate the energy integration model, which optimizes the heat recovery and the combined fuel, heat and power production by minimizing the total exergy depletion or the operating cost while computing the combined mass and energy integration (Gassner and Maréchal (2009)). The thermodynamic states and flow rates of the energy-flow and energy integration models are used in a post-calculation phase to size the equipment, estimate the cost and evaluate the performances of the process configuration. The performance indicators can be used in the frame of a multi-objective optimization framework, in which an evolutionary algorithm is implemented. A set of decision variables addressing technology choices and operating conditions of the process and utility system is provided for this. The computation sequence is depicted in Figure 1. As written in the figure, the optimization problem is formulated as a twostep optimization, the first optimization being a slave subproblem that minimizes the system operating cost by using process integration techniques with a MILP formulation, and the second optimization being the master problem which is non-linear and solved by an evolutionary genetic algorithm.

In its original form, the performance evaluation is limited to an economic model that rates the equipment in order to meet the thermodynamic design targets (Gassner and Maréchal (2009a)). In the present paper, we discuss how an LCA model can be formulated and implemented to systematically include the environmental life-cycle performance with respect to the detailed process design in the performance evaluation. In analogy with the economic model, it exploits the flowsheeting results like material and energy flows and equipment sizes to calculate the LCI of emissions and extraction flows associated to the process equipment and its operation. The life cycle inventory (LCI) is based on reference data in EcoSpold format (Frischknecht and Jungbluth (2007)) from the ecoinvent ${ }^{\circledR}$ life cycle inventories database (Frischknecht et al. (2005)). Finally, a life cycle impact assessment (LCIA) calculation for the obtained LCI is performed. The impact categories from the LCIA phase are used as indicators of the environmental performances of the process configuration, and can be considered in its multi-objective, environomic (i.e. energetic, environmental and economic) optimization (Gerber et al. (2010)).

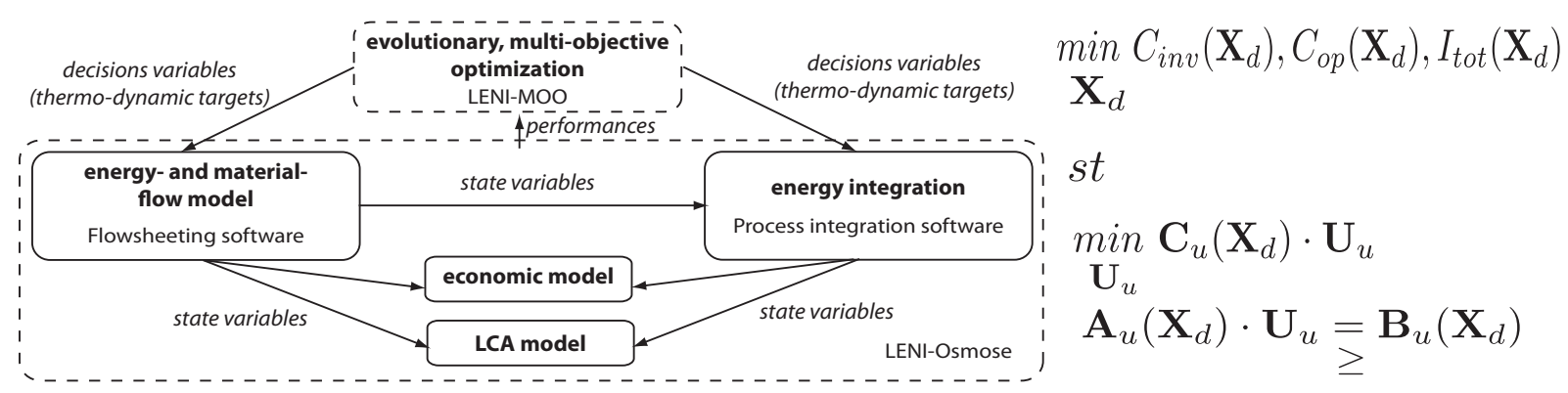

Figure 1: Architecture of the environomic process model

The developed general methodology for the construction and the integration of the LCA model within a thermo-economic model that complies with the ISO norm (ISO (2006a)) is depicted in Figure 2. The parts that are of particular importance to link the LCA model with the process design and configuration are displayed in bold. While listing the LCI flows through the system boundaries, it is crucial to identify to which process unit the flows are linked. This is 
necessary because they are then mathematically expressed as functions of the thermo-economic model. The scaling of impacts due to changes in operating conditions and size of the process equipment is therefore taken into account. A LCA function including all the mathematical expressions for LCI flows and the impact due to process equipment allows for calculating the whole LCI of a given process configuration. The ecoinvent ${ }^{\circledR}$ life cycle inventories database is used to find equivalences for the unit processes, elementary flows and impact assessment methods. The use of such a database allows for accounting for the induced off-site emissions.

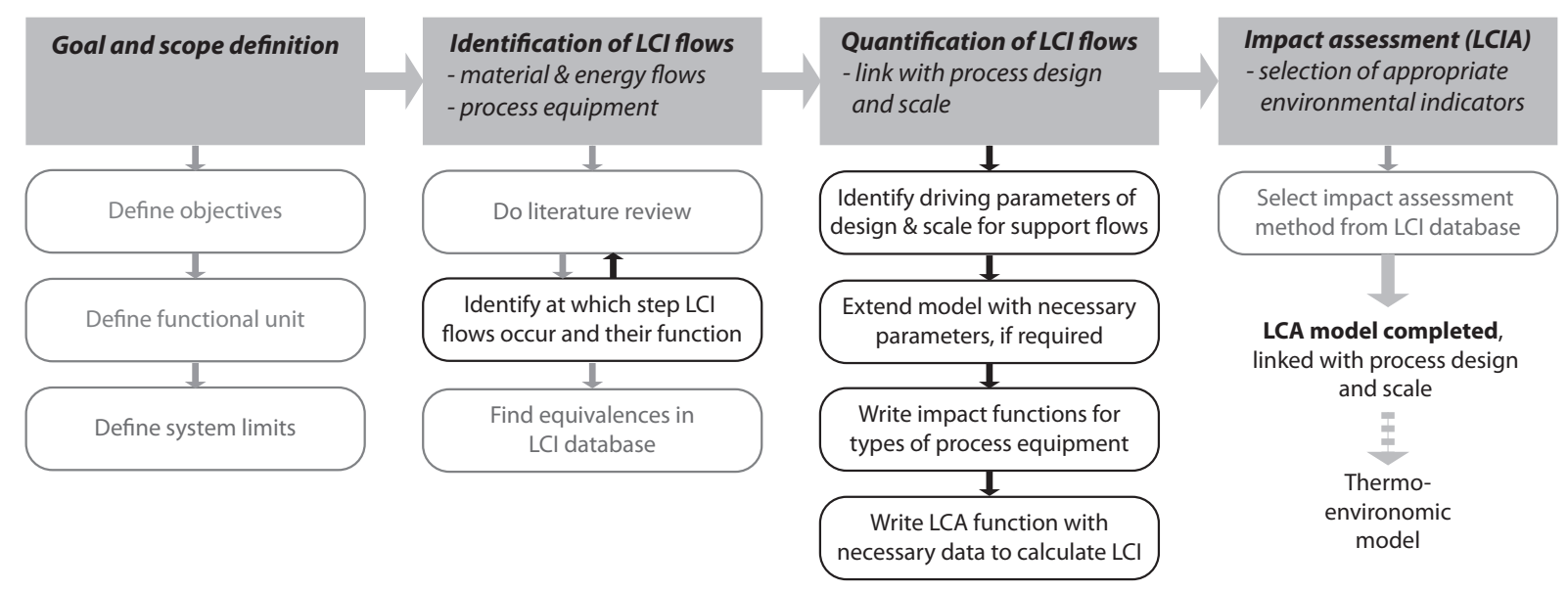

Figure 2: Developed general methodology for LCA model conception

This methodology is detailed by its application to the design of SNG production plants from lignocellulosic biomass in the following sections.

\subsection{Problem statement}

In the LCA community, this step is known as the goal and scope definition. The problem to be solved in this study is defined as the quantification of the environmental impacts associated with the production of SNG from lignocellulosic biomass and its relation to the changes in process design and configuration. Since the interest of the study is to focus on the influence of the design of the conversion process, the different possible allocations of produced SNG are not considered. Therefore, it would be natural to adopt a cradle-to-gate approach and consequently choose $1 \mathrm{MJ}$ of produced SNG as the functional unit (FU). However, this FU appeared to be not suitable for the following reasons:

- Due to electricity cogeneration from excess heat, both SNG and electricity are potential products whose relative yields depend on the process design. In an environomic optimization, adopting a strict cradle-to-gate approach with 1 MJ of SNG as FU leads to paradoxal results: as only the benefits of electricity generation from renewables is considered by an asymetric substitution of the multiple products, minimizing the impact of the SNG production is obtained by maximizing the electricity production to the expense of SNG, whose beneficial effect is not accounted for. Technical inefficiency and waste of renewable resources would thus be promoted. This problem is directly linked to the strict single-product based cradle-to-gate approach using $1 \mathrm{MJ}$ of SNG as the FU.

- Second reason is that the SNG production from lignocellulosic biomass is divided in two phases: the wood chips production and its conversion to SNG. The latter is thereby of particular interest, since it is mainly at this step that engineering decisions that impact the environment are taken. Using the MJ of wood as FU instead of the MJ of SNG neutralizes the impact of wood production while keeping the impact of logistics, which depends on the average collection distance related to the plant size. As a consequence, the effect of the 
process design and of the conversion efficiency is highlighted and the impact of the SNG produced will be considered by substituting its production as it will be the case for the electricity.

For these reasons, the chosen $\mathrm{FU}$ is the MJ of wood that enters the conversion process, considering that the function of the SNG plant is to convert wood into useful energy services (i.e. SNG and electricity). Therefore, the substitution for all the produced energy services is included. Regarding the SNG production, no special assumption regarding the allocation of the produced SNG is thereby required.

\subsection{Identification and quantification of LCI contributions}

The life cycle inventory is constituted by summing up the contributions of the LCI elements (or subsystems) that contribute to the life cycle chain. The defined system is taken as a basis to identify the different material and energy flows of the inventory. Since the LCI database proposes aggregated unit processes, it is not necessary to calculate manually each single emission or extraction for all the LCI elements. The amount of the LCI element is calculated, the emissions and extractions vector of the elementary flows is calculated by:

$$
E_{j, i}^{F U}=\mathbf{e}_{\mathbf{i}} \cdot M_{j}^{F U}
$$

where $E_{j, i}$ is the emission of the elementary flow $i$ for the LCI element $j, \mathbf{e}_{\mathbf{i}}$ is the specific emission or extraction per unit of LCI element, taken from the LCI database and $M_{j}^{F U}$ is the quantity of the LCI element $j$ per FU. For the single emissions or extractions that it is necessary to include as such in the LCI, the amount of the flow $E_{j, i}$ is directly calculated.

In the establishment of the LCI, three different categories of LCI elements are distinguished:

- Flows of the process flowsheet: Flows related to the process operation that are directly identified on the process flowsheet. (Examples: consumed or produced electricity, water required for chemical reaction)

- Flows of support materials: Flows related to the process operation that are required to support process operation and not included in process flowsheet. (Examples: auxiliary metal catalysts, combustion bed material)

- Process equipment: Equipment necessary to operate the process. (Examples: reactors, pumps, heat exchangers)

Details about the identification and quantification of these three categories are given in the following sections.

\subsubsection{Flows of the process flowsheet}

Identification Some of the LCI flows are directly calculated in the process flowsheet model used for the thermo-economic calculations.

In the example case, this includes the consumed wood, the produced SNG, the consumed or produced electricity and the required water. Substitutions for electricity production, if produced, and fossil natural gas (NG) production are considered. In Felder and Dones (2007), it is assumed that electricity comes from the Swiss mix, including the imports. The issue of substitution is however controversial. By substituting the impacts of the energy products, avoided fossil $\mathrm{CO}_{2}$ emissions are included, since they are assumed to be a consequence of any allocation of the produced SNG. For each element in the LCI, an equivalence is determined either from the LCI elements, termed as unit processes in the LCA community, or from the elementary flows of the 
LCI database. At this stage, the wood-to-SNG conversion process with the calculated input and output flows is already identified, and the parameters of the thermo-economic model influencing it are calculated.

Quantification In the case where the LCI flows are directly included in the process flowsheet, it is not necessary to develop a mathematical expression to calculate their quantities, and the values from the thermo-economic model are directly used for the LCA. These values are directly available as flow rates. Then, they are expressed per FU using the following equation:

$$
M_{j}^{F U}=\frac{\dot{m}_{j}\left(x_{d}\right) \cdot t_{\text {life }} \cdot r_{\text {operation }}}{F U_{\text {tot }}\left(x_{d}\right)}
$$

where $\dot{m}$ is the flow rate of the LCI flow taken from the process flowsheet and function of the decision variables of the optimization problem $x_{d}, t_{\text {life }}$ is the installation lifetime, here assumed to be 25 years, $r_{\text {operation }}$ is the yearly percentage of operation of the installation, here assumed to be $90 \%$ and $F U_{t o t}$ is the total $\mathrm{FU}$ quantity involved in the life cycle of the studied system, calculated by:

$$
F U_{\text {tot }}=\dot{f u}\left(x_{d}\right) \cdot t_{\text {life }} \cdot r_{\text {operation }}
$$

where $\dot{f} u$ is the flow rate of functional unit calculated by the process flowsheet, here the energy flow rate of the biomass, as well function of the decision variables $x_{d}$.

For the biomass logistics, we use GIS data for a specified location (Eclépens, Switzerland), which allow to evaluate the average shortest transport distance from the forest to the SNG plant for a given process scale (Stucki et al. (2010)).

\subsubsection{Flows of support materials}

Identification The use of LCA requires to extend the process flowsheet to include in the LCI the support materials that are not accounted for in the thermo-economic calculation, but that are nevertheless of environmental significance. Indeed, though not directly included in the process flowsheet, these flows are indirectly related to it.

For the example case, Figure 3 displays the different LCI flows crossing the system boundaries based on the inventory of Felder (2004) and Felder and Dones (2007). It includes the flows of support materials, but also the flows of the process flowsheet. The step of the SNG production at which they occur is also shown on the figure, which is a simplified schematic representation of the process detailed by Gassner and Maréchal (2009b).

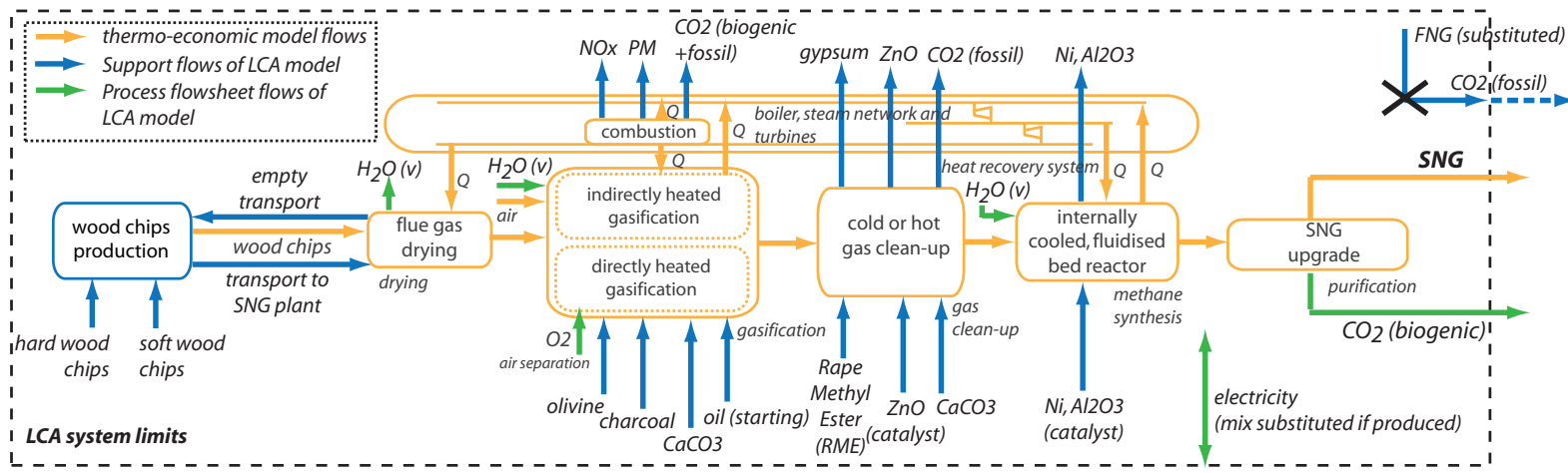

Figure 3: Flows of environmental concern added to the thermo-economic model 
Quantification These flows are not included in the process flowsheet but are required for the conversion. In this case, it is necessary to develop mathematical models to calculate their amounts. These mathematical expressions have to be based on the values calculated in the process flowsheet, and the amounts are therefore indirectly linked with it. Unlike for the equipment, no specific methodology can be developed for the impact scaling laws of the supporting flows identified in the LCI. Therefore, a case-by-case approach has to be adopted in order to identify to which parameters of the flowsheet model these flows are linked. However, we can identify the parameters that have an influence on the amount of support materials:

$$
M_{j}^{F U} \sim M_{j, \text { init }}\left(x_{d}\right), \dot{\alpha}_{j}, t_{l i f e}, r_{\text {operation }}
$$

where $M_{j, \text { init }}$ is the initial quantity of the auxiliary material $j$, function of the decision variables $x_{d}$, and $\dot{\alpha}$ is the turnover of the material.

For example, the flows related to the process operation that are auxiliary materials consumed by the reactors are assumed to be directly linked to the size of the vessels, and a general formulation is developed for this type of support flow, which is used in Equation 2:

$$
\dot{m}_{j, r m}=V_{\text {reac }}\left(x_{d}\right) \cdot \dot{\alpha}_{j, r m}
$$

where $\dot{m}_{j, r m}$ is the flow rate, or the quantity, of the auxiliary material used in the reactor, $V_{\text {reac }}$ is the volume of the reactor, which is a function of the decision variables $x_{d}$, and $\dot{\alpha}_{j, r m}$ is the consumption rate of the material per unit of reactor volume and time. The latter is assumed to be a constant and calculated from the data available for the pilot-scale process from Felder (2004) and Felder and Dones (2007).

\subsubsection{Process equipment}

In addition to the LCI of the process flows, the environmental impact induced by the equipment has to be accounted for. For SNG production from lignocellulosic biomass, it mainly consists in reactors, heat exchangers, pumps or compressors.

Identification An inventory of all major process equipment is first set up, and a specific type is assigned to each unit. For consistency with the thermo-economic model, the inventory is based on the equipment that is rated and quoted in the economic model. For each type of process equipment, equivalent LCI elements are found in the LCI database. If no equivalence is found, the quantity of materials required for the construction of the process equipment and its transport needs to be estimated, and the equivalent LCI contribution will be deduced from the corresponding materials and transports.

Quantification Our goal is to calculate the life cycle inventory of each proces equipment considering its size and operating conditions. Such inventory functions will be based on existing inventories of similar equipment and should take the process conditions into account.

In classical LCA, emissions and impacts of the process equipment is most often linearly scaled with equipment size. This assumption is yet not justifiable in general, since the emissions are likely to be proportional to the amount of materials used to produce the process equipment. It is thus better suited to scale the emissions related to the process equipment with a more general form that is similar to the formulation for equipment costs estimation, where a specific exponent will be used for each single emission, i.e.:

$$
\frac{E_{j, i}}{\mathbf{E}_{\mathbf{j}, \text { ref }, \mathbf{i}}}=n \cdot\left(\frac{A_{j}\left(x_{d}\right)}{n \cdot \mathbf{A}_{\mathbf{j}, \mathbf{r e f}}}\right)^{\mathbf{k}_{\mathbf{j}, \mathbf{i}}} \cdot \mathbf{c}_{\mathbf{j}}, A_{j} \in\left[A_{j, \min } A_{j, \max }\right]
$$




$$
n=\left[\operatorname{int}\left(\frac{A_{j}}{\mathbf{A}_{\mathbf{j}, \max }}\right)+1\right]
$$

where $E_{j, i}$ is the scaled emission of the elementary flow $i, \mathbf{E}_{\mathbf{j}, \mathbf{r e f}, \mathbf{i}}$ the emission of the reference LCI dataset, $A_{j}$ the functional parameter related to the size of the process equipment $j$ in the validated range $\left[A_{j, \min } ; A_{j, \max }\right]$, function of the decision variables $x_{d}, n$ the number of units required in parallel, $\mathbf{A}_{\mathbf{j} \text {,ref }}$ the value of this functional parameter for the reference dataset, $\mathbf{k}_{\mathbf{j}, \mathbf{i}}$ the scaling exponent of the elementary flow $i$ and $\mathbf{c}_{\mathbf{j}}$ a correction factor that represents the specific operating conditions or the unit type. The formulation of Equation 6 reduces to classical linear scaling by setting $n=1, k=1, c=1$, but also allows for taking positive and negative economy of scale into account ( $n<1$ and $n>1$, respectively). In these and all other equations of this paper, the variables that represent LCI database entries are displayed in bold, while the ones that are calculated from the process conditions are in italic.

The scaling is done for each single emission or extraction of the LCI, and not on the final impacts in order to track or analyze single substances. Finally, these emissions have also to be expressed per FU:

$$
E_{j, i}^{F U}=\frac{E_{j, i}}{F U_{t o t}}
$$

The general methodology for identifying suitable parameters for Equation (6) is summarized step-by-step in Figure 4. Whenever the information available in the LCI database allows, the parameters of Equation (6) are identified by parameter identification. This is the case if datasets for the same type of process equipment are available for (at least) two different scales. If not enough datasets are available, appropriate values for the parameters must be identified by other means. If similar economy of scale for equipment cost and environmental impact can be expected from simplified rating considerations, the size exponent from cost correlations can be used as an approximation. Values of such coefficients may be for example found in Turton et al. (1998) and Ulrich (1996). Emissions due to maintenance, assembly, transports and end-of-life of process equipment are also calculated for each type of process equipment.

The relevancy of this approach for the impact scaling of the process equipment is illustrated in Figure 5(a) and 5(b) by two examples, a shell-and-tube heat exchanger and a compressor. For the heat exchanger, no LCIA data are available at two different sizes or more from the LCI database. Detailed design data are taken from a heat exchanger manufactured for an industrial chemical process at 10 different sizes, size being represented by the exchange area in $\mathrm{m}^{2}$. It is composed by two materials, stainless steel and unalloyed steel, which quantities are calculated for each exchange area using the design data. Then the resulting impact is calculated using the LCIA data for the two materials from the LCI database, using the single score of the Ecoindicator99$(\mathrm{h}, \mathrm{a})$. The results per unit of exchange area are displayed in Figure 5(a). A comparison of the impact calculated by the design data with a linear extrapolation and with a power extrapolation using a costs exponent from the literature (Turton et al. (1998) and Ulrich (1996)) for one of the design points at $13 \mathrm{~m}^{2}$ is as well presented.

To confirm the validity of the methodology, a second example is shown in Figure 5(b) scaled as a function of the electricity consumption in $\mathrm{kW}_{e}$. Details for the LCIA data can be found in Steiner and Frischknecht (2007). This example provides a comparison between the conventional LCA approach for impact scaling and the proposed approach in case that only one dataset at one particular size is known. In the figure, a second LCI dataset available for another size of the compressor is used to validate the scaling methodology. The conventional LCA approach uses a linear extrapolation $(k=1)$ to estimate the impact at any other scale. With the proposed approach based on the analogy with equipment costing, a power impact scaling law is used to extrapolate the impacts of the compressor at any size. If only one LCIA dataset is known, it is not possible to calculate the exponent directly. However, since similarity between cost and 


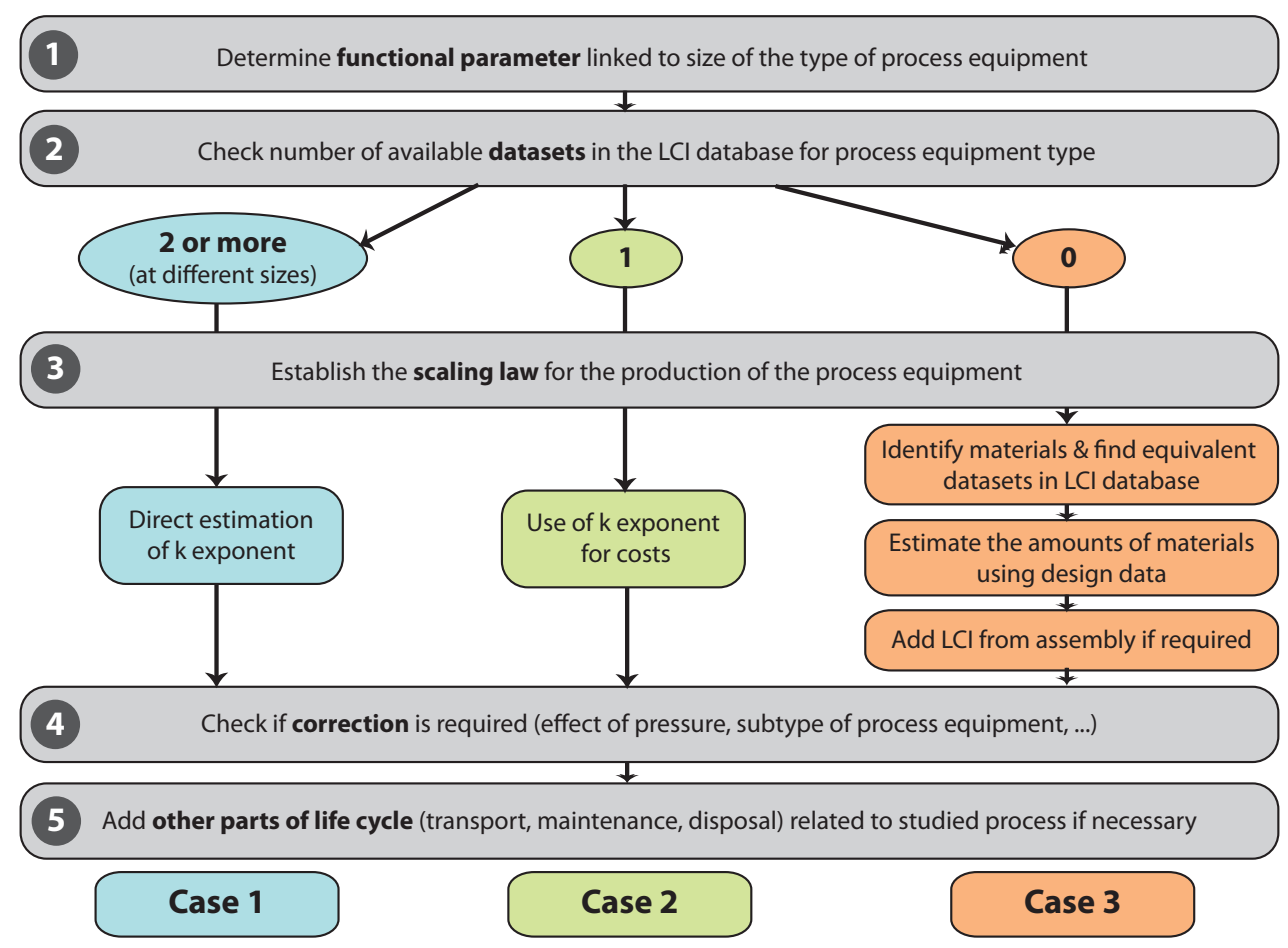

Figure 4: Methodology to establish scaling laws for process equipment

impact scaling laws is assumed, the costs exponent from the literature (Turton et al. (1998) and Ulrich (1996)), can be used to estimate the impact of the compressor at any size. This gives an exponent value of 0.6 .

Using the smaller compressor as reference and extrapolating the impact per $\mathrm{kW}_{e}$ (assessed by the single score of the Ecoindicator99-(h,a) method in this example) with the correlation, Figure 5 (b) demonstrates that the power law for the scaling is more accurate than the linear scale-up of conventional LCA, which would assume a constant impact per $\mathrm{kW}_{e}$. To include uncertainty parameters in this evaluation and show the relevance of the costs analogy, a Monte-Carlo simulation has been performed on the compressor at 4 and $300 \mathrm{~kW}_{e}$ using the uncertainty data included in the LCI datasets. The uncertainty linked with the linear and the power extrapolation is assumed to be constant and equal to the one of the known dataset at $4 \mathrm{~kW}_{e}$, while the control point at $300 \mathrm{~kW}_{e}$ has its own uncertainty. The confidence interval at $95 \%$ obtained by this simulation and expressed per $\mathrm{kW}_{e}$ is shown on Figure 5(b), for both the dataset and the extrapolation. This highlights that the accuracy of the power law extrapolation meets the confidence interval of the datapoint, which is not the case for a conventional linear scaling.

These two examples show the validity of the assumption of the power law for the impact scaling and its analogy with the costs scaling. It however suggests that if enough data are available, it is however better to directly calculate the exponents $\mathbf{k}_{\mathbf{j}, \mathbf{i}}$ than using the costing exponent, which is actually an average approximation, since there is still a difference between the absolute value of the dataset and the costing analogy. Consequently, this option should be retained only in the case the LCI database does not contain enough data to perform the scaling of the process equipment considered.

Similar investigations have been conducted for other types of process equipment. These include boilers and reactors. These other examples demonstrate as well that the use of power laws for the impact scaling following the economy of scale provide a better estimation of the impact than using a linear scaling law $(k=1)$.

These considerations highlight that the developed scaling laws depend on the available data in the LCI database and the exponent is not always calculated in the same way. For heat 


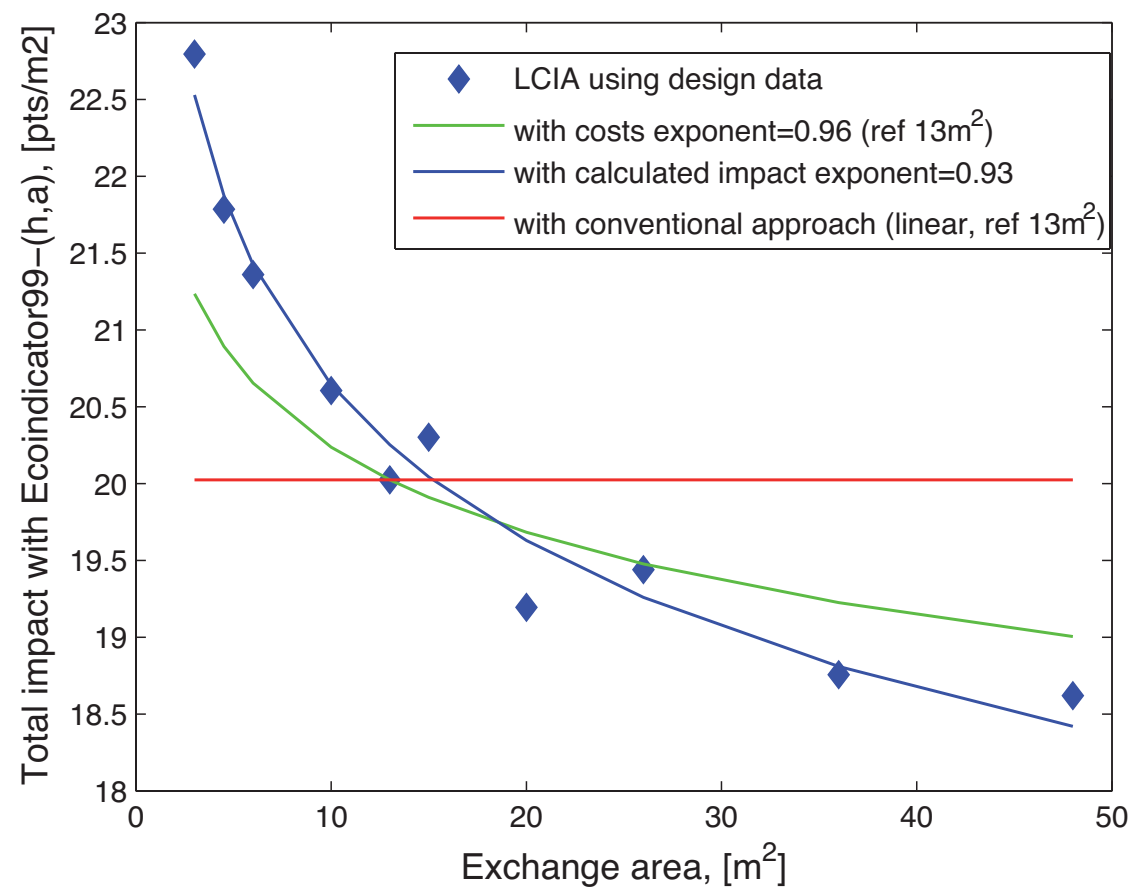

(a) Impact scaling for a shell and tube heat exchanger, using costing analogy and linear extrapolation for one point, and comparison with LCIA conducted using design data (Case 3)

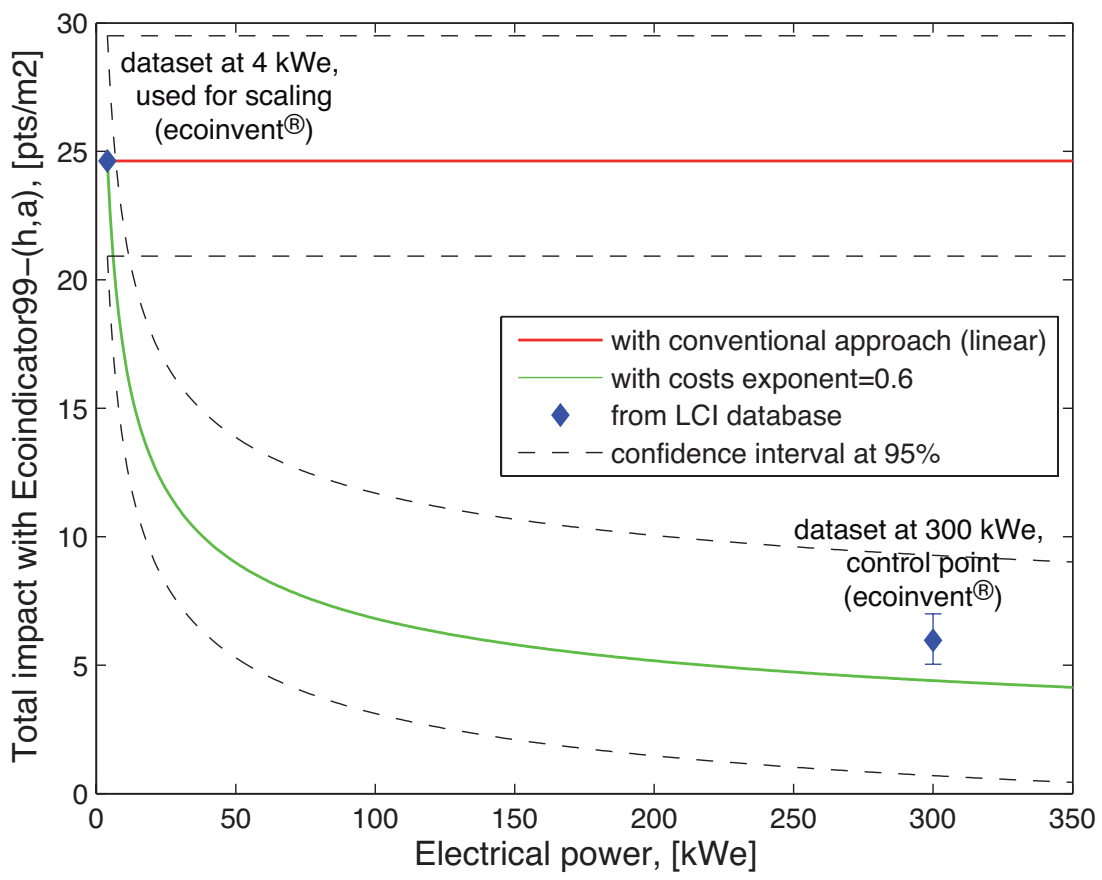

(b) Impact scaling for a compressor, using costing analogy and linear extrapolation, and comparison with LCIA data from ecoinvent ${ }^{\circledR}$ (Case 1)

Figure 5: Examples of impact scaling laws for different types of process equipment

exchangers, reactors and membranes, the quantity of materials required for their production can be determined directly from the thermo-economic model and the LCI database equivalences for these materials (Classen et al. (2007) and Hischier (2007)). For boilers and compressors, extensive 
datasets from the LCI database are available at two different sizes (Steiner and Frischknecht (2007) and Dones et al. (2007)) and allow for the direct calculation of the exponent of the impact scaling law. For pumps and filters, only one extensive data set from the LCI database is available (Dones et al. (2007) and Hässig and Primas (2007)), and the costing exponent from Turton et al. (1998) and Ulrich (1996) can be used as an approximation for the exponent of the impact scaling law. All the correction factors are based on cost data from Turton et al. (1998) and Ulrich (1996) since there are currently no datasets in the LCI database for different operating conditions or equipment types. Details for the development of the impact scaling laws for the different types of process equipment are available in Appendix A.

A summary of the major process equipments that were identified for the production of SNG and included in the LCI is shown in Table 1. The table also lists their functional parameters, and which correction is applied to the impact if necessary. The value of the different functional parameters and of the other parameters required to calculate the correction factors are directly taken from the thermo-economic model.

\begin{tabular}{|c|c|c|c|}
\hline Type & A (functional parameter) & c (correction factor) & scaling (Fig. 4) \\
\hline Boiler & thermal power $[\mathrm{kWth}]$ & - & Case 1 \\
Compressor & electrical power [kWe] & type (screw, axial, centrifugal) & Case 1 \\
Filter & volume flow [Nm3] & - & Case 2 \\
Heat exchanger & exchange area [m2] & operating pressure [bar] & Case 3 \\
Membrane & membrane area [m2] & - & Case 3 \\
Pump & electrical power [kWe] & operating pressure [bar] & Case 2 \\
Reactor & volume (diameter $/$ height) [m3] & operating pressure [bar] & Case 3 \\
\hline
\end{tabular}

Table 1: Included process equipment with their corresponding functional parameters and aspects taken into account for the correction factor

\section{$2.3 \quad$ Life Cycle Impact Assessment}

The LCIA step computes the environmental impact by aggregating the vector of the different elementary flows of emissions or extractions in indicators of environmental significance. These indicators are termed impact categories, and the aggregation is done by using an impact assessment method, which is a matrix containing the weightings for the different elementary flows:

$$
\begin{aligned}
& \begin{array}{lllll}
\mathbf{F}_{\mathbf{1}, \mathbf{1}} & \ldots & \mathbf{F}_{\mathbf{1}, \mathbf{n}} & E_{1} & I_{1}
\end{array} \\
& {\left[\begin{array}{ccc}
\ldots & \ldots & \ldots
\end{array}\right] \cdot[\ldots]=[\ldots]} \\
& \begin{array}{lllll}
\mathbf{F}_{\mathbf{m}, \mathbf{1}} & \ldots & \mathbf{F}_{\mathbf{m}, \mathbf{n}} & E_{n} & I_{m}
\end{array}
\end{aligned}
$$

where $\mathbf{F}_{\mathbf{i}, \mathbf{j}}$ is the weighting factor to convert the LCI emission $i$ into the impact category $j, E_{i}$ is the emission or extraction $i$ calculated in the LCI, and $I_{j}$ is the impact category $j$ of the impact assessment method. In the present example, two different impact assessment methods are selected from the LCI database and implemented in the computational framework. These are the Ecoindicator99-(h,a) detailed by Goedkoop and Spriensma (2000) and the Ecoscarcity06, whose principle is described in Brand et al. (1998). The first one is a damage-oriented approach and measures the impact on three endpoint categories, namely the human health, the ecosystem quality and the resources. The hierarchist weighting set, assumed to represent the scientific vision, is used here. The second impact assessment method is based on the scientifically supported goals of the Swiss environmental policy. No impact assessment method considering only the single issue of greenhouse gases emissions is used. Indeed, these emissions are included and weighted in the two chosen impact assessment methods. This is justified by the fact that sustainable biofuels refer not only to the reduction of greenhouse gases emissions with respect to the fossil fuels. It should also be ensured that their production and use does not result in an increase of other types of environmental impacts when compared with the fossil fuels. These other types of impact are hence as well considered in the chosen impact assessment methods. 
The impact categories of the two chosen methods are detailed in Table 2. Since these methods propose an additional weighting step and the aggregation into a single score, the single scores of both methods are used as global indicators for the variation in environmental impacts of the process. The aggregation step into a single score $I_{t o t}$ is formulated as:

$$
I_{\text {tot }}=\sum_{l=1}^{m} I_{l} \cdot \mathbf{w}_{\mathbf{l}}
$$

where $\mathbf{w}_{\mathbf{l}}$ is a factor used for the normalization and weighting of the different impact categories.

\begin{tabular}{|c|c|c|}
\hline Impact assessment method & Impact categories & Weighting $\mathbf{w}_{\mathbf{i}}$ \\
\hline Ecoindicator99-(h,a) & Human Health & 400 \\
& Ecosystem Quality & 400 \\
& Resources & 200 \\
\hline Ecoscarcity06 & Air emissions & 1 \\
& Surface water emissions & 1 \\
& Groundwater emissions & 1 \\
& Top soil emissions & 1 \\
& Energy resources & 1 \\
& Natural resources & 1 \\
& Deposited waste & 1 \\
\hline
\end{tabular}

Table 2: Impact assessment methods implemented in the LCA model, with their selected impact categories

At this stage, the individual contribution to the different impacts of each LCI element is calculated, and can further be retrieved for results interpretation and the identification of the principal contributing unit processes.

\section{Application to the example case}

In order to investigate the effects of an industrial process design on LCIA, the developed LCA methodology is first compared with a classical LCA for SNG production in Section 3.1.In a second step, we then demonstrate how our approach for LCIA modelling can be used for a multi-objective process optimization with respect to thermodynamic, economic and environmental performance, in Section 3.2. Finally, the importance of the substitution of energy services in multi-product systems and of the LCIA weighting are discussed in Section 3.3.

\subsection{Comparison of our methodology with conventional LCA}

First, the developed LCA methodology is compared with the conventional LCA methodology that is using mean data from literature to estimate the LCIA impact of the plant. A scenario using the LCI data from Felder and Dones (2007) is adapted to the system boundaries of the present study to account for NG substitution. The LCIA results for this scenario are then compared at a scale $8 \mathrm{MW}_{t h}$, scale being expressed by the thermal capacity of input wood for the process, with the LCIA results for a conservative industrial process design (base case scenario), which has been developed with the thermo-economic process model as described in Gassner and Maréchal (2009b). This scenario is evaluated with and without combined heat and power production from excess heat by a steam Rankine cycle. This allows for comparing the impact of the by-products and of the process integration. 


\subsubsection{Results and discussion}

The results are compared in bar charts where, on the left side, the overall impacts are presented in relative percentage using as reference the results of the conventional LCA. On the right, we report the impact indicator expressed in points. Positive numbers refer to the harmful impacts of the process considering the life cycle, while negative numbers refer to the beneficial impacts that are avoided when substituting the product and services of the process.

Ecoscarcity06 Figure 6 compares the impact assessment of the conventional LCA with the methodology presented here using the Ecoscarcity06 method with detailed process contributions.

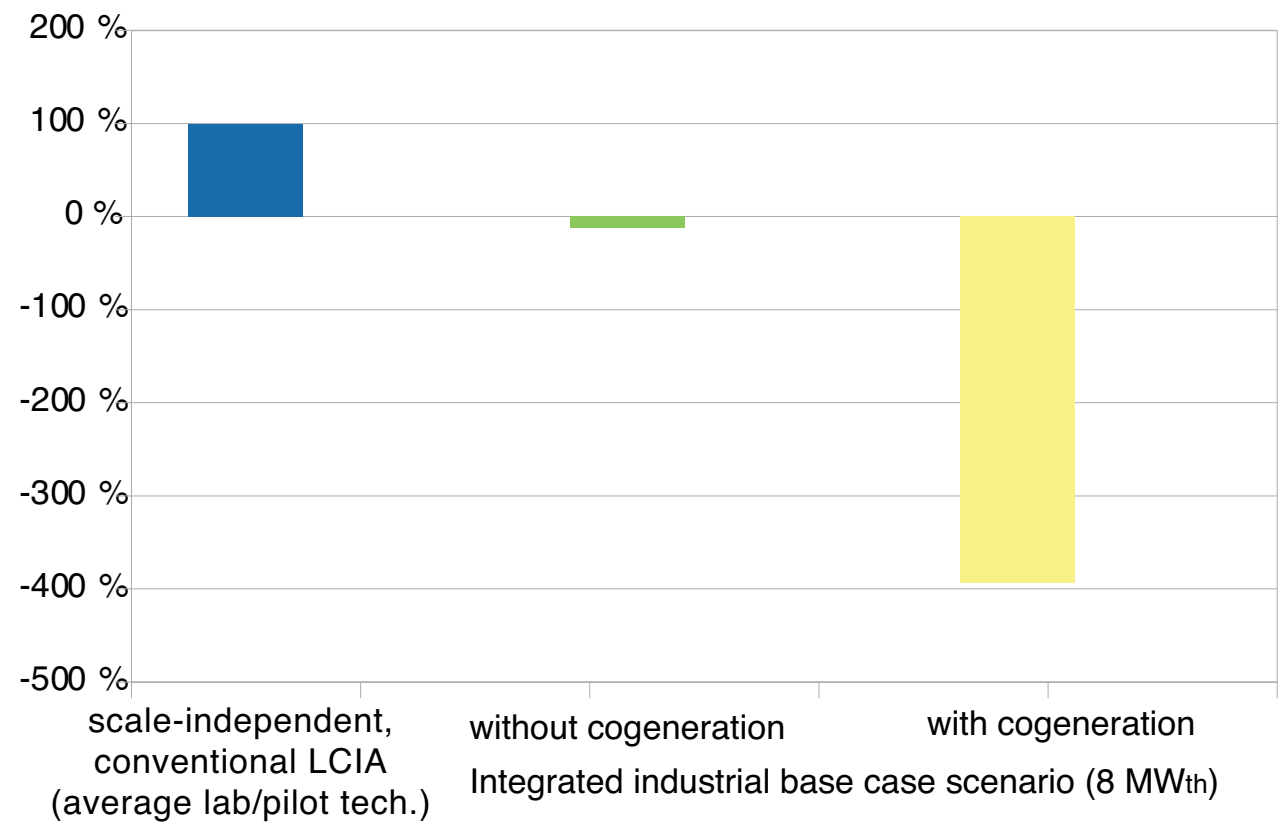

(a) Overall impacts

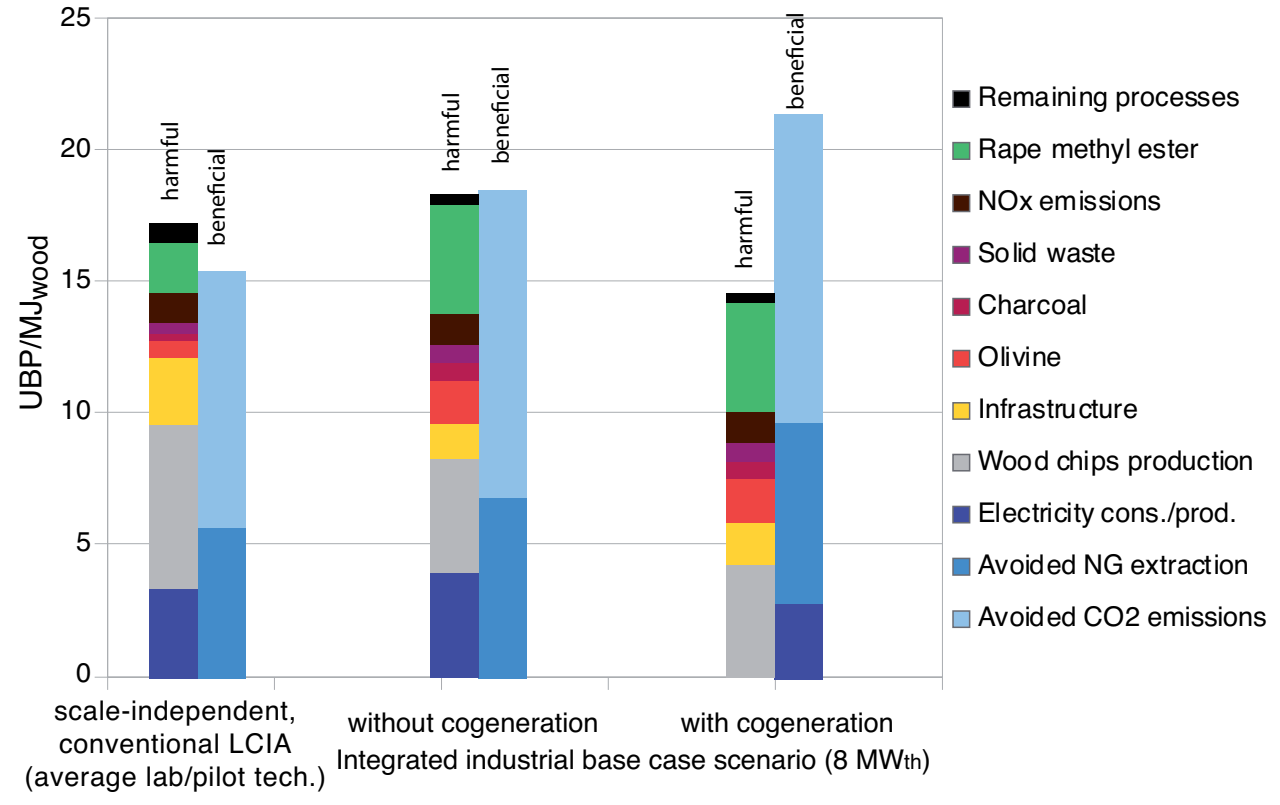

(b) Detailed contribution

Figure 6: Comparison of LCIA results obtained by conventional LCA and the proposed methodology for Ecoscarcity06, single score, with detailed process contributions 
The relative differences between the conventional LCA and the base case scenario without and with combined heat and power production (CHP) are significant. The scenario described by the conventional LCA results in a positive impact that means that the plant is harmful for the environment, even if the substitution for NG is accounted for. For the base case scenario without a Rankine cycle, there is an impact reduction of $110 \%$ compared to the reference (conventional LCA). For the base case scenario with a Rankine cycle, the reduction is of $490 \%$. These important reductions are due to both positive and negative impacts that compensate each another. Negative (i.e. beneficial) contributions are due to the substitution of NG by biogenic SNG and to the electricity cogeneration for the base case scenario with a Rankine cycle.

The differences between the conventional LCA and the base case scenario without and with a Rankine cycle are mainly due to the improved conversion efficiency obtained by applying process design method, which has a direct influence on the quantity of SNG produced per unit of biomass. In the base case scenarios, the efficiency is considerably higher because the energy integration is optimized in the process design. As a direct consequence, the environmental impact of the process is lower when compared to a conventional LCA based on a pilot plant design as published in the literature. For the industrial base case scenario without a Rankine cycle, the increase in efficiency more than compensates the increased positive (i.e. harmful) impacts of the equipment required to increase the efficiency of the original design. The comparison of the base scenarios with and without electricity cogeneration further highlights the environmental benefit of a proper process integration. When compared with the conventional LCA, the Ecoscarcity06 impact is decreased by more than $300 \%$.

Apart from this considerable benefit obtained from an improved conversion efficiency and regarding other contributions, it can be seen that the impact due to the wood chips production is lower for the conventional LCA. This is due to a different evaluation of the transport of wood chips in the developed methodology. While Felder and Dones (2007) use a constant transport distance, we use GIS-based data that allow to evaluate the average transport distance from the forest to the SNG plant for a given process scale (Stucki et al. (2010)). Another important difference is the contribution of the infrastructure, which is higher in case of conventional LCA. This is also due to the different approach: while Felder and Dones (2007) scaled down linearly the total infrastructure of a methanol plant, we use a more detailed impact scaling method which differentiates each piece of process equipment, sized according to the process design. Other effects of the process design on the environmental impacts are the calculation of the auxiliary material flows associated with the reactors sizes (i.e. olivine, charcoal and solid waste) and of the rape methyl ester (RME) consumed in the produced gas cleaning unit. These flows have a higher contribution on the impact for the base case scenarios than for the conventional LCA, which is however compensated by the increase of the process efficiency. The reported differences can not be explained by the assumptions made in the LCI but are explained by the LCA models as proposed here.

Ecoindicator99-(h,a) Figure 7 compares the impact assessment by conventional LCA with the developed methodology for the Ecoindicator99-(h,a) method with detailed process contributions. Impact is set as negative to avoid misinterpretation of the results, since the overall impact of both studied scenarios and the conventional LCA is negative (i.e. beneficial).

Though less than with Ecoscarcity06, the relative difference between the conventional LCA and the base case scenarios is important: the reduction varies between 70 and $80 \%$ from the conventional LCA to the base case scenarios. As observed on Figure 7, this is due to the higher process efficiency, which leads to a higher SNG production per unit of biomass and therefore to a higher natural gas substitution for the base case scenario than for the conventional LCA.

Unlike for Ecoscarcity06, the differences between the scenarios with and without a Rankine cycle are around $10 \%$ and thus smaller. This is due to the lower weighting of the electricity consumption or production, which has a much smaller contribution with Ecoindicator99-(h,a) 


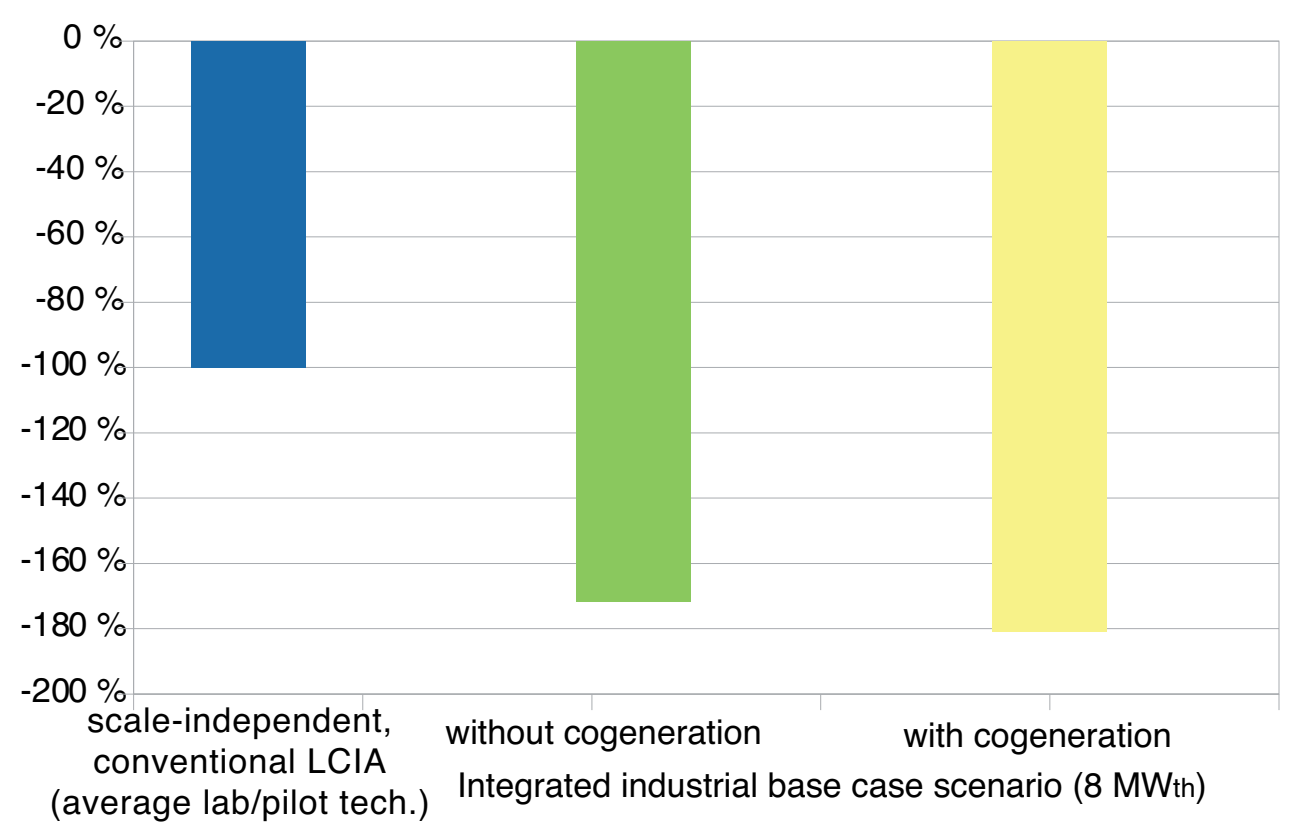

(a) Overall impacts

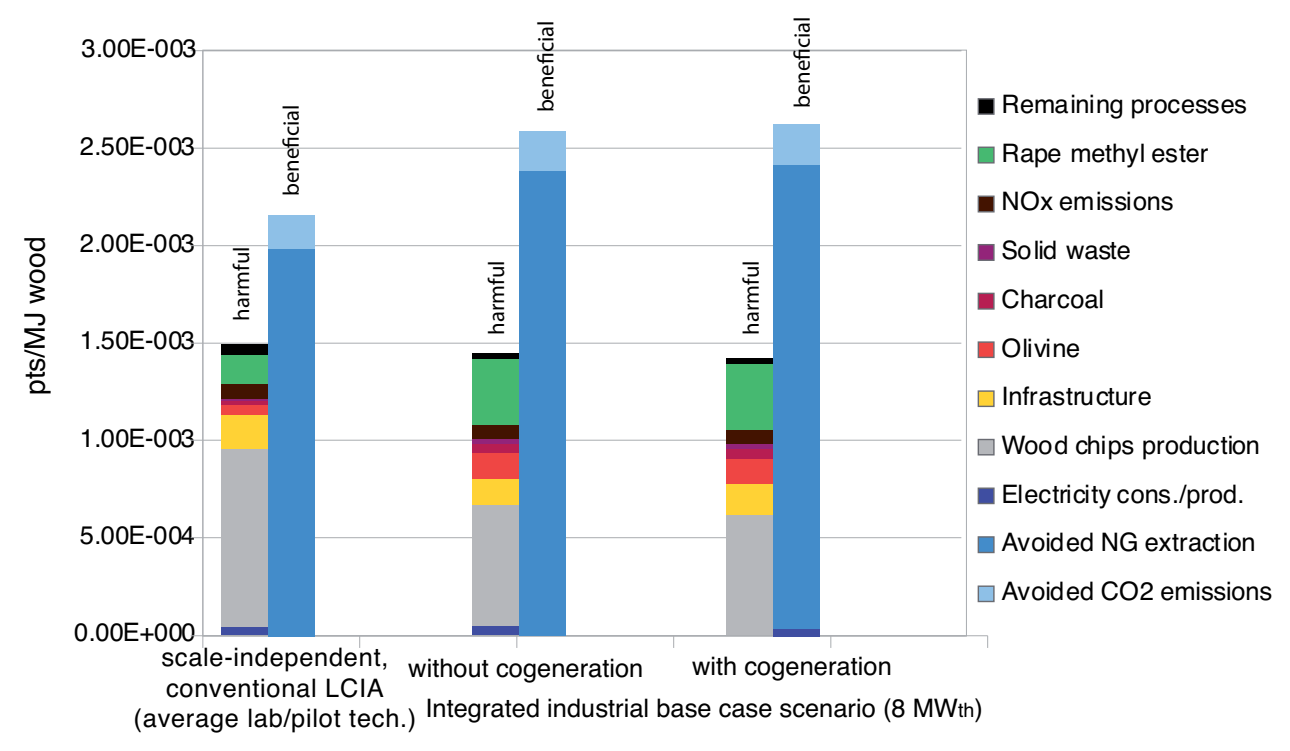

(b) Detailed contribution

Figure 7: Comparison of LCIA results obtained by conventional LCA and the proposed methodology for Ecoindicator99-(h,a), single score, with detailed process contributions

than with Ecoscarcity06.

\subsection{Multi-objective environomic optimization}

As outlined in the introduction, one of the principal interests of linking process design and LCA is the possibility to consider environmental criteria in the technology choices at an early stage of the design and integrate them in the optimization procedure. In order to study the influence of the developed LCA methodology on the optimal process configurations, a multi-objective optimization of the process superstructure is conducted with an evolutionary algorithm with nondominated set (Molyneaux et al. (2010)). As thermoeconomic objective, the biomass profitability $C_{\text {profitability }}\left[€ / \mathrm{MWh}_{b m}\right]$ defined as the net profit obtained from the resource conversion is used. In analogy to the choice of the FU for the environmental impacts, this indicator relates best to 
the function of the process that is to convert a resource into useful energy services, and not only in a single product:

$$
\begin{aligned}
C_{\text {profitability }}= & \epsilon_{S N G} \cdot C_{S N G}+\epsilon_{e l} \cdot C_{e l}-C_{b m} \\
- & \frac{\Delta h_{R M E}^{0} \dot{m}_{R M E}^{+} \cdot C_{R M E}+\dot{m}_{O 2}^{+} \cdot C_{O 2}}{\Delta h_{b m}^{0} \dot{m}_{b m, d a f}^{+}} \\
& -\frac{C_{\text {salaries }}+0.05 \cdot C_{G R}+\frac{\left(1+i_{r}\right)^{n}-1}{i_{r}\left(1+i_{r}\right)^{n}} \cdot C_{G R}}{t_{a} \cdot \Delta h_{b m}^{0} \dot{m}_{b m, d a f}^{+}} \\
\text {with: } \quad \epsilon_{S N G} & =\frac{\Delta h_{S N G}^{0} \dot{m}_{S N G}^{-}}{\Delta h_{b m}^{0} \dot{m}_{b m, d a f}^{+}} \\
\epsilon_{e l} & =\frac{\dot{E}^{-}}{\Delta h_{b m}^{0} \dot{m}_{b m, d a f}^{+}}
\end{aligned}
$$

in which $C_{S N G}, C_{e l}, C_{R M E}$ and $C_{b m}$ correspond to the prices of SNG, electricity, RME and biomass [ $€ / \mathrm{MWh}], C_{O 2}$ to the price of oxygen [€/kg], $C_{\text {salaries }}$ to the employees' total yearly salaries [€/year] and $C_{G R}$ to the investment cost from grass roots [€] as calculated by the economic model of Gassner and Maréchal (2009b). $\epsilon_{S N G}$ and $\epsilon_{e l}$ represent the product yields of SNG and electricity, $\Delta h^{0}$ the lower heating value on dry, ash free (daf) basis $\left[\mathrm{MJ} / \mathrm{kg}_{d a f}\right]$ and $\dot{m}$ the mass flow $[\mathrm{kg} / \mathrm{s}]$ of streams that enter $\left(^{+}\right)$or leave $\left(^{-}\right)$the system. The maintenance cost is thereby assumed to amount to $5 \%$ of the investment per year, and the annualised investment is discounted at an interest rate $i_{r}[\%]$ over the economic lifetime $n$ [years] of the plant at an annual operational time $t_{a}$ [h/year]. As discussed by Gassner (2010), $C_{\text {profitability }}$ - or an alternative formulation of a break-even cost for biomass in which the substraction of $C_{b m}$ is omitted - is the most coherent indicator to evaluate the thermoeconomic design objective in a polygeneration context since it accounts for the value of all products in the same way, which would not be the case if the production costs of SNG were used. All assumed prices and parameters for the evaluation of Equation (11) are summarised in Table 3.

\begin{tabular}{llr}
\hline Parameter & & Value \\
\hline Interest rate & $i_{r}$ & $6 \%$ \\
Discount period & $n$ & 15 years \\
Plant availability & & $90 \%$ \\
Operators $^{\mathrm{a}}$ & & $4^{\mathrm{b}}$ per shift \\
Operator salary & & 60 '000€ per year \\
Maintenance costs & $C_{b m}$ & $5 \%$ of $C_{G R}$ per year \\
Wood price $\left(\Phi_{\text {wood }}=50 \%\right)$ & $C_{R M E}$ & $33 € \mathrm{MWh}^{-1}$ \\
Biodiesel price & $C_{e l}$ & $105 € \mathrm{MWh}^{-1}$ \\
Electricity price (green) & $C_{O 2}$ & $180 € \mathrm{MWh}^{-1}$ \\
Oxygen price & $C_{S N G}$ & $($ Kirschner, 2009$)$ \\
SNG price & $C$ & $120 € \mathrm{MWh}^{-1}$ \\
\hline
\end{tabular}

${ }^{a}$ Full time operation requires three shifts per day. With a working time of five days per week and 48 weeks per year, one operator per shift corresponds to 4.56 employees.

${ }^{\mathrm{b}}$ For a plant size of $20 \mathrm{MW}_{t h \text {,wood }}$. For other production scales, an exponent of 0.7 with respect to plant capacity is used.

Table 3: Assumptions for process economics.

As environmental indicator, the single score of the cumulated environmental impacts described in Equation (10) is chosen. To highlight the importance of the choice of the environmental objective function, we perform the optimization using once the single score of Ecoscarcity06, 
and once the single score of Ecoindicator99-(h,a). Table 4 displays the decision variables and their associated validity ranges.

\begin{tabular}{|l|c|c|c|}
\hline Name & Integer & range & unit \\
\hline Gasification technology & yes & FICFB, pFICFB, CFB & - \\
Gas cleaning technology & yes & cold, hot & - \\
Thermal capacity as input wood (size) & no & {$[5 ; 200]$} & MW $_{t h}$ \\
Air dryer inlet temperature & no & {$[453 ; 513]$} & $\mathrm{K}$ \\
Wood humidity at gasifier inlet & no & {$[0.1 ; 0.3]$} & - \\
Gasification pressure & no & {$[1 ; 30]$} & bar \\
Methanation pressure & no & {$[1 ; 30]$} & bar \\
Methanation inlet temperature & no & {$[573 ; 673]$} & $\mathrm{K}$ \\
Methanation outlet temperature & no & {$[573 ; 673]$} & $\mathrm{K}$ \\
Wobbe index after CO2 removal & no & {$[13 ; 13.8]$} & $\mathrm{kWh} / \mathrm{Nm}^{3}$ \\
High (retentate) pressure of membrane 1 & no & {$[5 ; 50]$} & $\mathrm{bar}$ \\
High (retentate) pressure of membrane 2 & no & {$[5 ; 50]$} & $\mathrm{bar}$ \\
High (retentate) pressure of membrane 3 & no & {$[5 ; 50]$} & $\mathrm{bar}$ \\
Molar stage cut of stage 2 & no & {$[0.2 ; 0.6]$} & - \\
Molar stage cut of stage 3 & no & {$[0.2 ; 0.6]$} & - \\
Remainder of purification inlet to stage 2 & no & {$[0 ; 1]$} & - \\
Steam production pressure & no & {$[40 ; 120]$} & $\mathrm{bar}$ \\
Steam superheat temperature & no & {$[623 ; 823]$} & $\mathrm{K}$ \\
Number of steam utilization levels (integer) & no & {$[0 ; 3]$} & - \\
Steam bleeding temperature & no & {$[323 ; 523]$} & $\mathrm{K}$ \\
Steam condensation temperature & no & {$[293 ; 383]$} & $\mathrm{K}$ \\
Minimum temperature difference in HEX network & no & {$[1 ; 2]$} & $\mathrm{K}$ \\
\hline
\end{tabular}

a FICFB: indirectly heated Fast Internally Circulating Fluidized Bed gasification

b pFICFB: indirectly heated pressurized FICFB gasification

c CFB: directly heated Circulating Fluidized Bed gasification

$\mathrm{d}$ applies only to CFB technology

e applies only to pFICFB and CFB technologies

Table 4: Decisions variables and associated ranges used for the multi-objective optimization. See Gassner and Maréchal (2009b) for a detailed definition of the variables.

Three gasification and two gas cleaning technologies are proposed as discrete decision variables. They represent different development stages for SNG production from lignocellulosic biomass. They have been described in Gassner and Maréchal (2009b) and are included in the process superstructure. The other decision variables relate to the process operating conditions.

\subsubsection{Results and discussion}

The Pareto curve resulting from the multi-objective optimization are shown in Figure 8(a) and 8(b). Four clusters representing different technological options of the superstructure are displayed in different marker types. The process size associated with the optimal process configurations is as well displayed using a color gradient. 


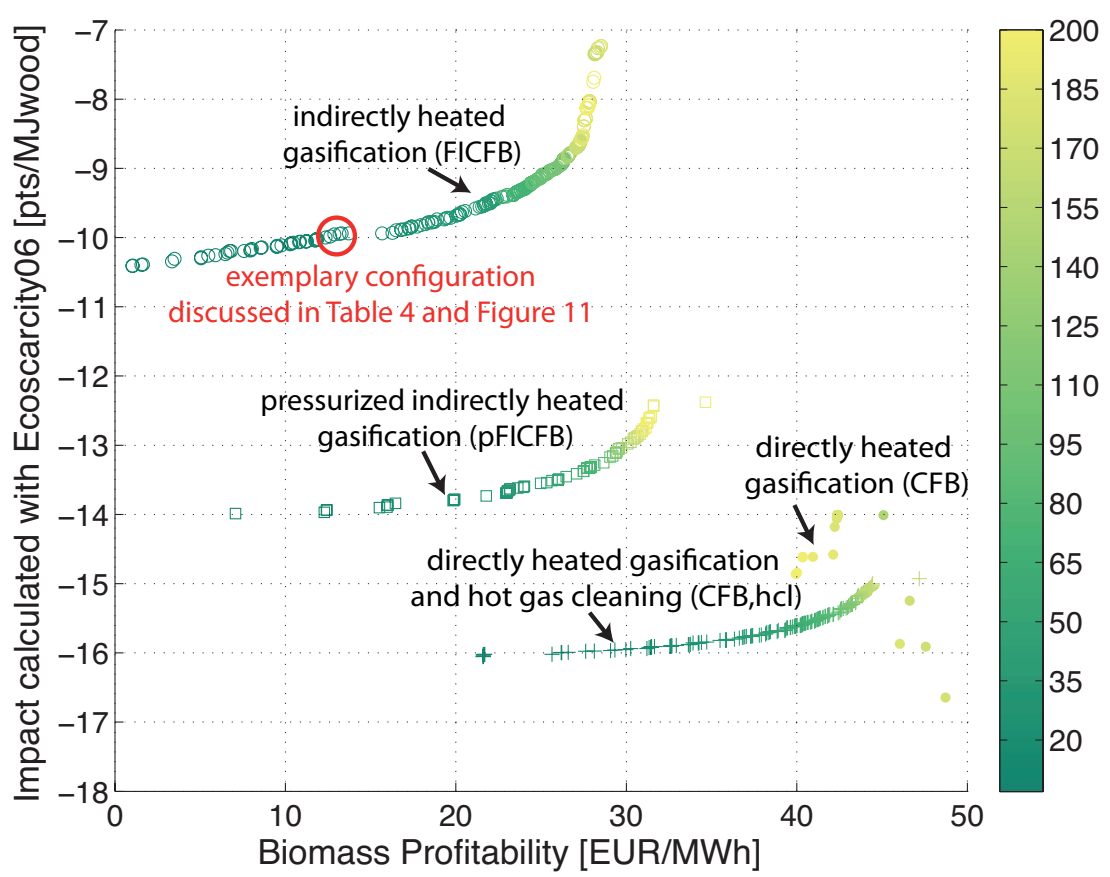

(a) Ecoscarcity06 as the environmental objective

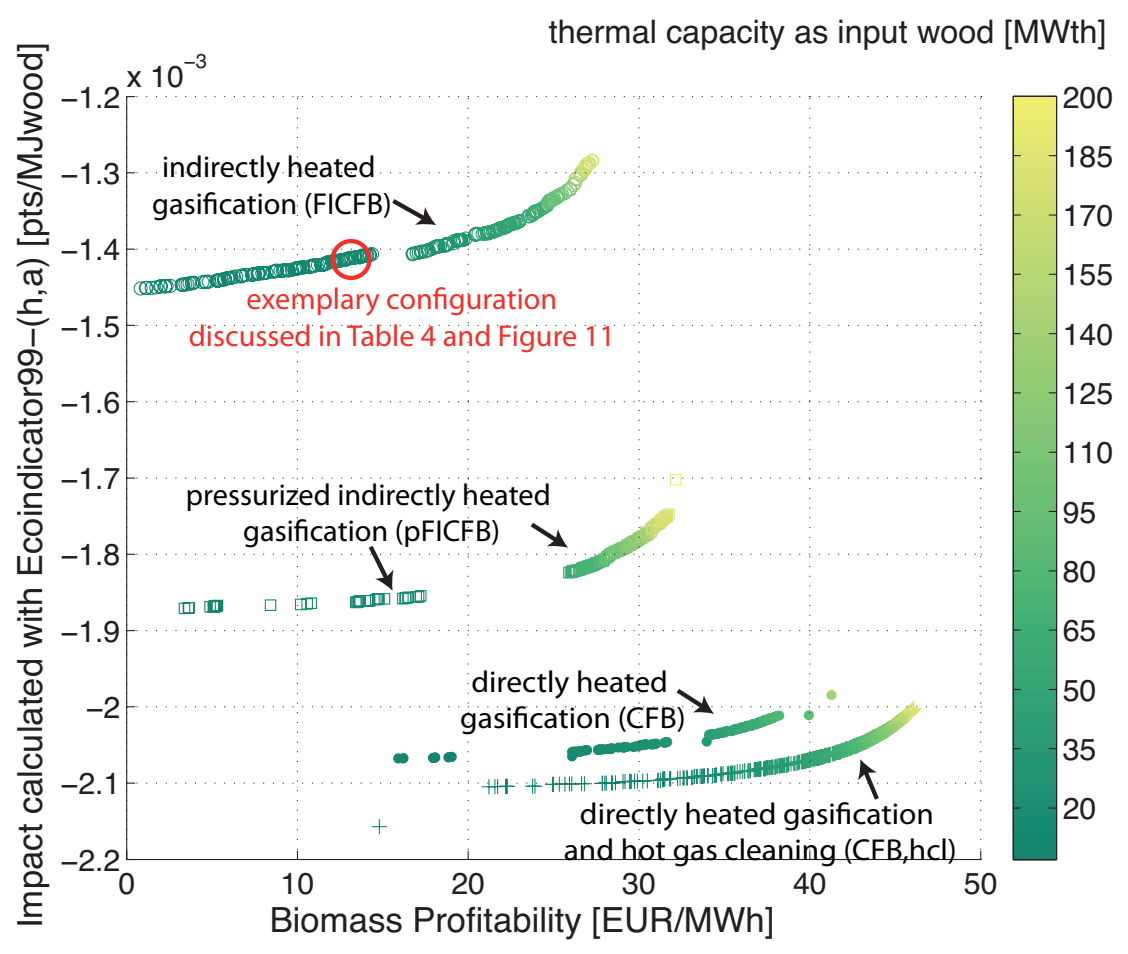

(b) Ecoindicator99-(h,a) as the environmental objective

Figure 8: Results of multi-objective optimization using one LCIA method as the environmental objective, biomass profitability as the economic objective, at multiple scale

From these figures, it clearly appears that there is a trade-off between environmental impacts and biomass profitability. This is mainly due to the effect of the process size, since an increase in the size leads simultaneously to an increase of the environmental impacts but also to an increase of the biomass profitability. The increase of the profitability is mainly due to the economy of scale. Although the contribution of infrastructure to the environmental impact is as well decreasing 
with the scale, this effect is compensated by an increase of the contribution of biomass logistics (e.g. the wood transport), by an increase of the auxiliary materials such as olivine and charcoal and by a decrease of the electricity produced. To illustrate this, the specific contributions are displayed for two points of the FICFB cluster, one at $5 \mathrm{MW}_{t h}$ and one at $200 \mathrm{MW}_{t h}$ in Figure 9, using the Ecoscarcity06 indicator.

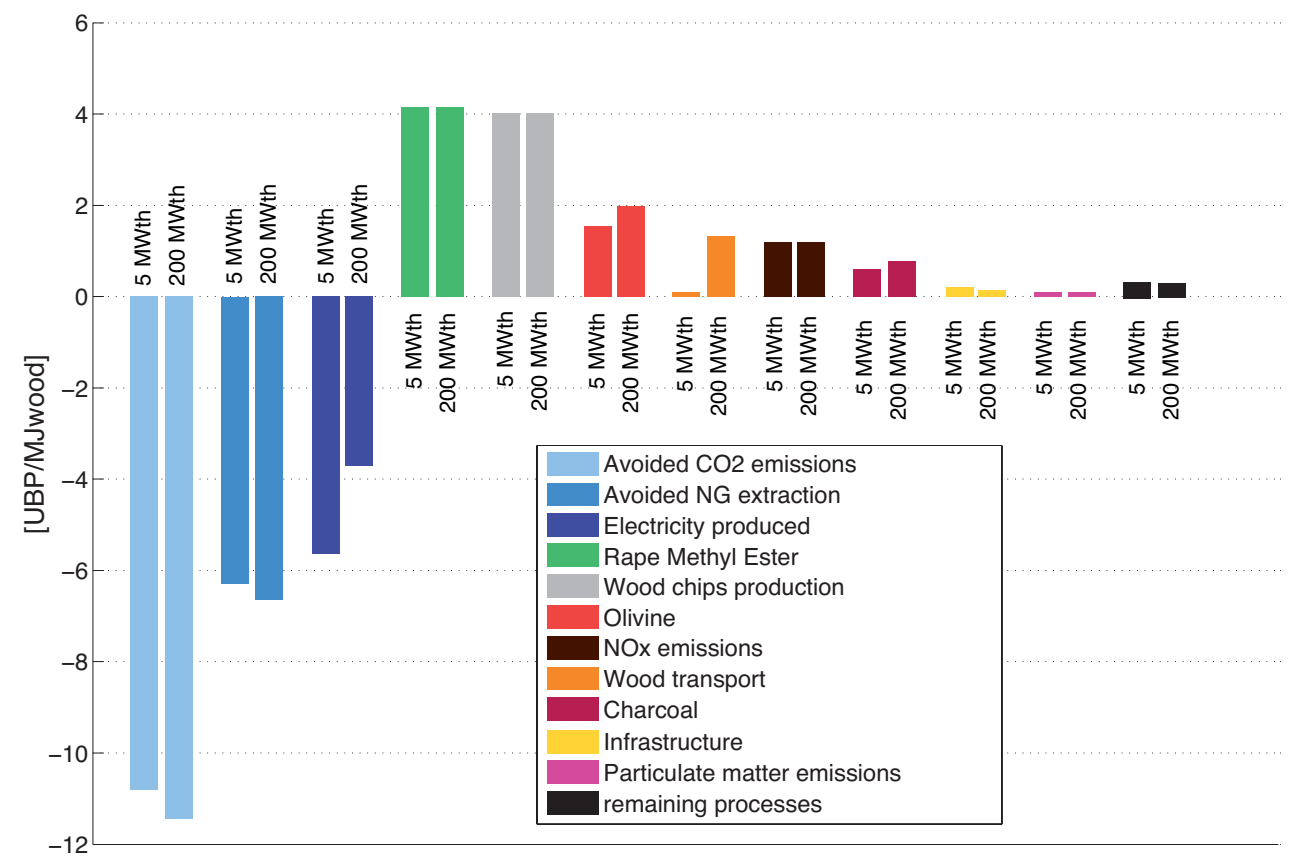

Figure 9: Impact contribution for two configurations using FICFB at different scales (The legend is presented in the same order than the contributions displayed on the graph).

Both the decrease of the contributions for infrastructure and the increase for auxiliary materials required for gasification is a direct consequence of the adopted methodology which links the LCI flows to the process flowsheet by Equation (4) and (5). More precisely, the latter is an effect of the gasifier scaling, whose specific volume per unit of FU increases with size. This has a direct effect on the trade-off between economical and environmental aspects, and could not have been highlighted with a conventional LCA methodology.

Another advantage of the developed methodology is the possibility of analyzing both the economics and the environmental impact of technology evolutions. Pressurizing the indirectly heated gasification technology would allow for an important impact reduction due to a more compact gasifier design. The volume reduction reduces consequently the amount of auxiliary materials required for gasification, i.e. olivine and charcoal. Moreover, since pFICFB operates under pressurized conditions, the volume of the gases coming from the gasifier and its associated amount of RME required for gas cleaning is drastically reduced. Switching from indirect gasification technology to direct, steam-oxygen blown gasification (CFB) reduces the impact even further, since this last technological option has an increased efficiency and produces therefore more SNG per unit of wood. In addition, as CFB gasifier do not release combustion gases to the atmosphere, the nitrogen oxides impacts are removed. The effects of these three technological evolutions are illustrated by displaying the contributions for three points at a fixed scale of $60 \mathrm{MW}_{\text {th }}$ for FICFB, for pFICFB, and for CFB with hot gas cleaning in Figure 10, using the Ecoindicator99-(h,a). 


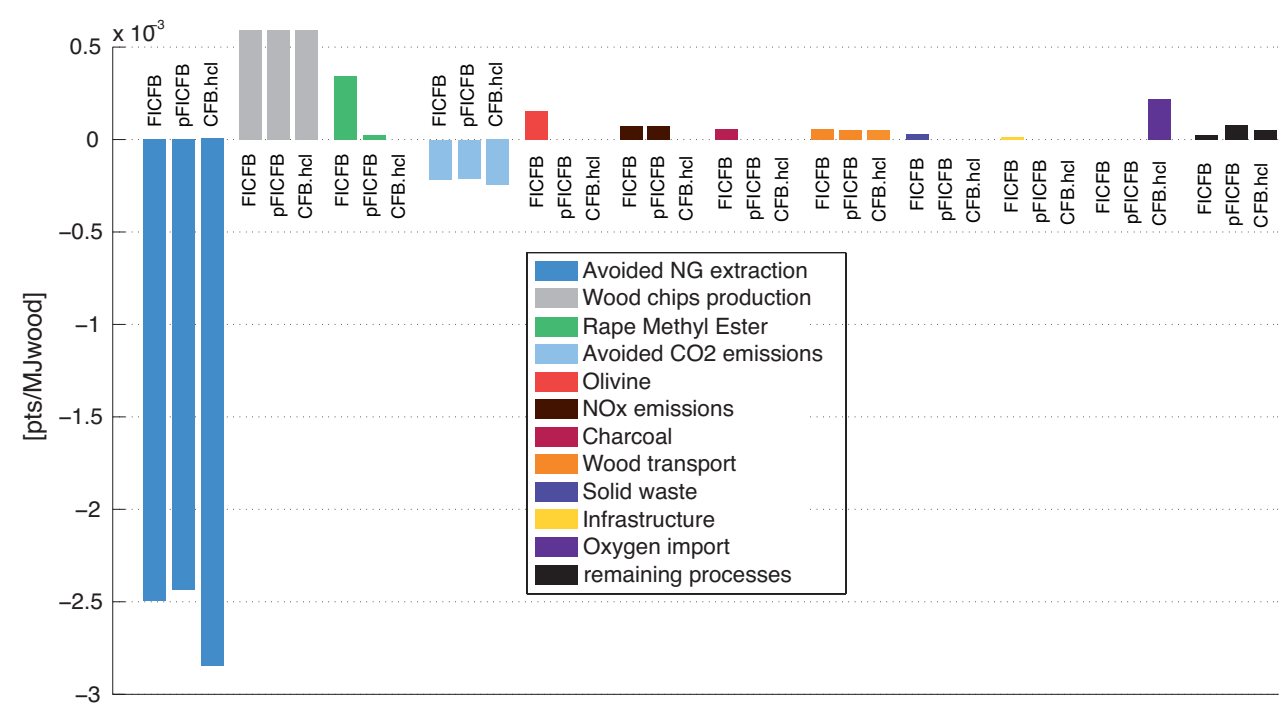

Figure 10: Impact contribution for Ecoindicator99-(h,a) for a $60 \mathrm{MW}_{t h}$ configuration using different technologies (The legend is presented in the same order than the contributions displayed on the graph).

A last aspect which highlights the influence of the integration of environmental impacts in the optimization procedure is the influence of the environmental objective in the optimal process design. While the Pareto curves show similar trends for both environmental objective functions and the same ranges for biomass profitability, the actual optimal process configurations are different depending on which environmental objective function is chosen. To illustrate this, two points at the same scale but using different environmental objective functions can be compared. For more details on point selection, their characteristics are detailed in Table 5. The impact contributions of these two points are displayed in Figure 11(a) and 11(b).

\begin{tabular}{|l|c|c|}
\hline & Ecoscarcity06 & Ecoindicator99-(h,a) \\
\hline Gasification technology & FICFB & FICFB \\
Process size [MW $\mathrm{MW}_{t h}$ ] & 12.7 & 12.3 \\
Profitability [EUR/MWh] & 13.7 & 13.8 \\
Total electricity production $\left[\mathrm{MW}_{e}\right]$ & 0.761 & 0.015 \\
Relative electricity production $\left[\mathrm{MW}_{e} / \mathrm{MW}_{t h}\right]$ & 0.06 & 0.001 \\
Total SNG production [MW] & 7.9 & 8.6 \\
Relative SNG production [MW/MW $\left./ \mathrm{MW}_{t h}\right]$ & 0.620 & 0.703 \\
\hline
\end{tabular}

Table 5: Comparison of two optimal process configurations identified on Figure 8 for different environmental objective functions 


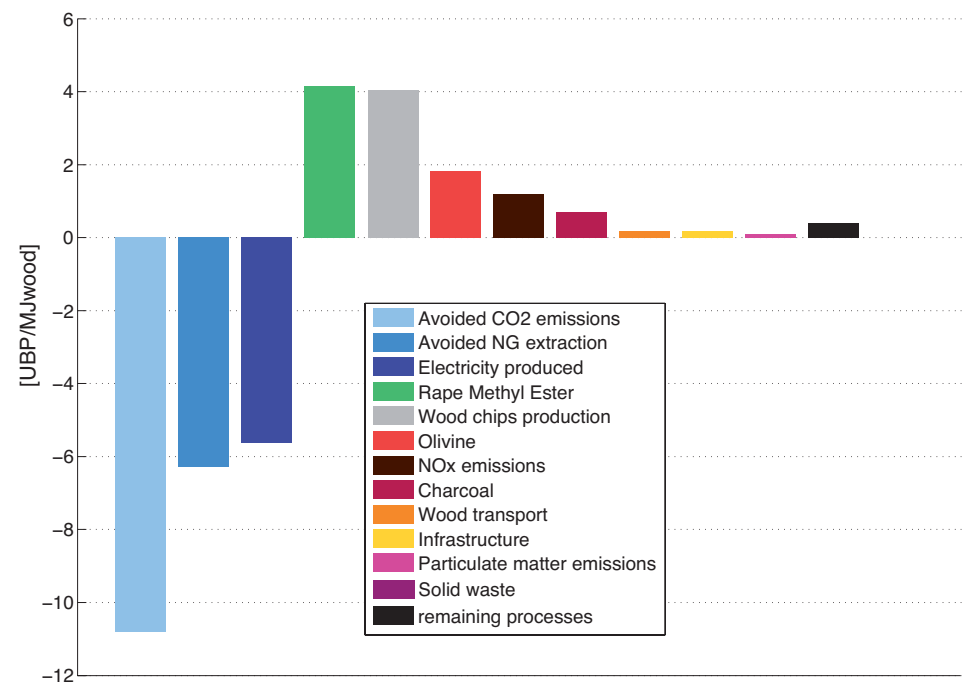

(a) Ecoscarcity06 as the environmental objective

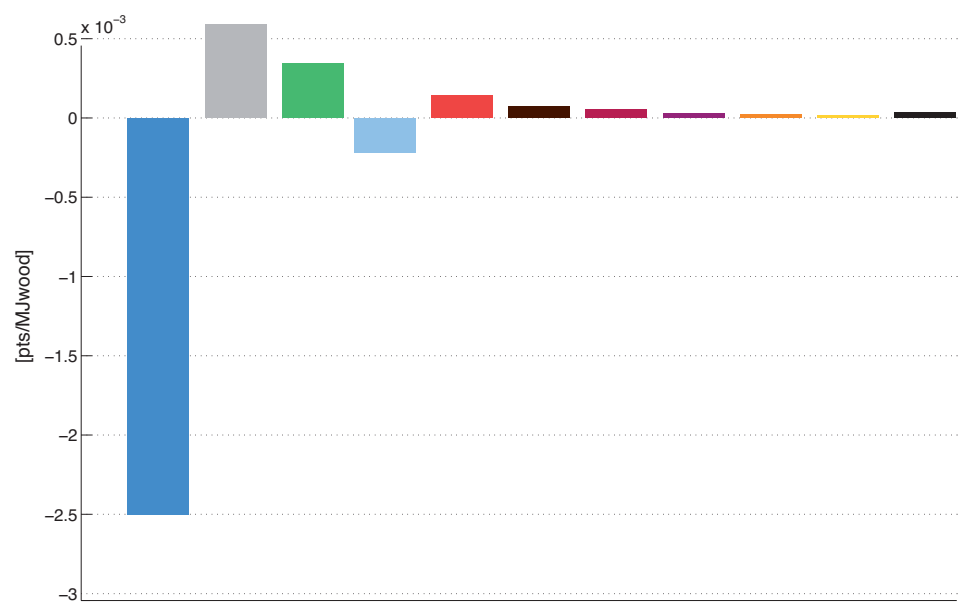

(b) Ecoindicator99-(h,a) as the environmental objective

Figure 11: Impact contribution for a $12 \mathrm{MW}_{t h}$ configuration using FICFB identified on Figure 8 (The legend is presented in the same order than the contributions displayed on the graph).

The optimal process configurations using Ecoscarcity06 lead to an increased electricity production and reduced SNG production, while Ecoindicator99-(h,a) favors clearly the SNG production. This shows how the integration of environmental impacts in the optimization procedure can influence the engineering decisions related to the final process design. Considering that the two cases have the same economical value, the design decisions may be taken with respect to the environmental criterion.

These last results also demonstrate the importance of selecting the appropriate substitution scenarios for energy services.

\subsection{Substitution weighting in multi-product systems}

The question arises whether the reduction in environmental impact is strictly correlated with the increase in efficiency. To address this issue, the optimization strategy can be changed by calculating the trade-off between the environmental objective function and the production of both energy services. In order to remove the effects on environmental impacts due to scaling, the calculations are made for a $20 \mathrm{MW}_{t h}$ fixed process size, the other decision variables remaining unchanged. The multi-objective optimization is using three objectives in which one is 
the environmental impact, the two other being the specific SNG production and the electricity yields to be maximized. Multi-objective optimization is performed twice with respect to both Ecoscarcity06 and Ecoindicator99-(h,a) as the environmental objective to be minimized. The results are displayed in Figure 12(a) and 12(b), for the FICFB cluster and a process scale of 20 $\mathrm{MW}_{t h}$. In these figures, the thermodynamically optimal process configurations are displayed as well. It corresponds to the flowsheets that maximise the overall 'chemical' efficiency, in which the contributions of SNG and electricity are weighted by the conversion of SNG to electricity in a state-of-the-art natural gas combined cycle with an efficiency of $55 \%$.

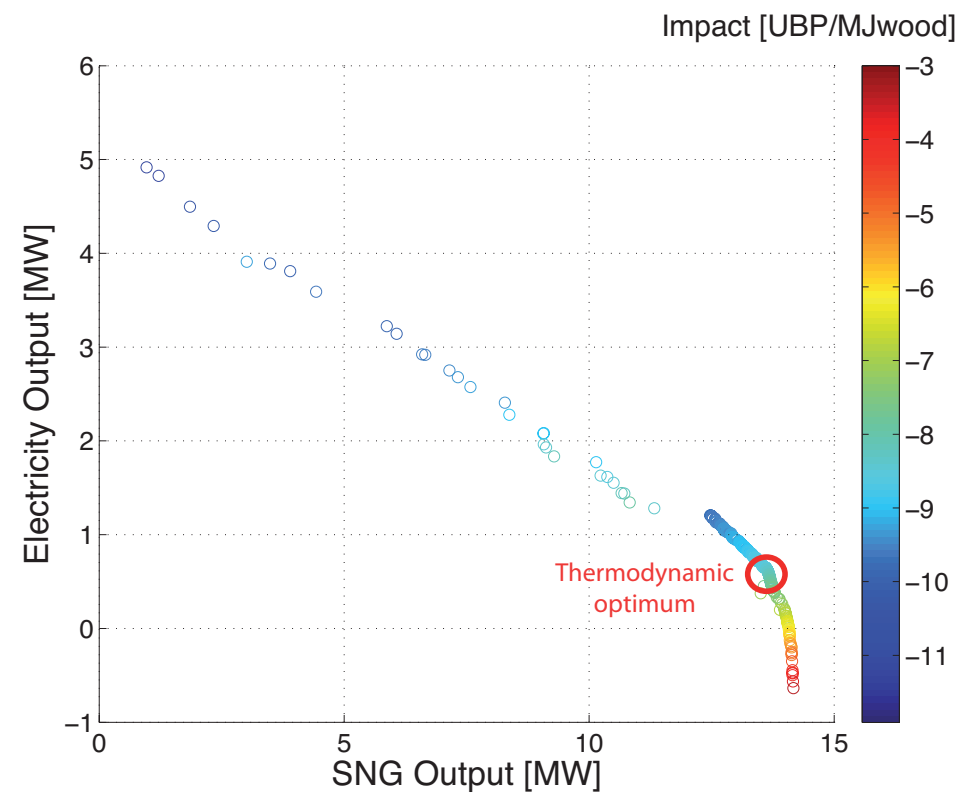

(a) Ecoscarcity06 as the environmental objective

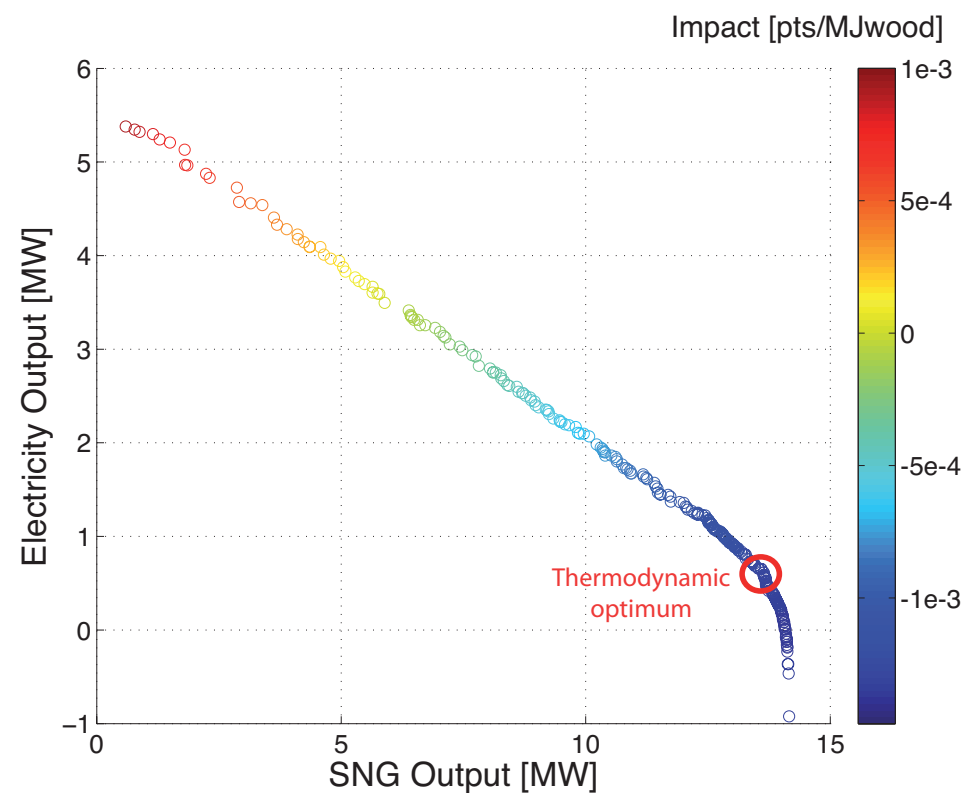

(b) Ecoindicator99-(h,a) as the environmental objective

Figure 12: Results of multi-objective optimization using one environmental objective, SNG and Electricity output as other objectives, at a fixed $20 \mathrm{MW}_{t h}$ scale for FICFB.

The results show a clearly opposite trade-off between the two energy services. While Ecoscarcity06 favors the electricity production, Ecoindicator99-(h,a) objective is favoring the SNG production. 
These differences are due to the different weighting of energy services in the LCIA step. The thermodynamic optimum has an overall efficiency of $73.7 \%$ in terms of SNG-equivalent, with a share of $13.59 \mathrm{MW}$ of SNG and $0.65 \mathrm{MW}_{e}$ of electricity. Due to the different weighting of SNG and electricity in the LCIA methodologies, this does not correspond to any of the environmental optima, especially in the case of Ecoscarcity06 where it is situated in the middle of the range of environmental impacts associated with optimal configurations. These results demonstrate therefore that in the case of a process producing multiple energy services, reducing the environmental impacts can not be assimilated uniquely to an increase of process efficiency.

This result also highlights the important issue linked with the substitution weighting, which leads to favor the electricity production for one environmental indicator and the SNG production for the other. This difference is due to the higher weighting attributed to the use of fossil resources in the Ecoindicator99-(h,a). As a consequence, Ecoindicator99-(h,a) favors the substitution of NG over the electricity substitution of the Swiss mix, which has a relatively low fossil resource content. The opposite is the case for Ecoscarcity06 that attributes a higher weight to the substitution of nuclear electricity which represents an important share of the Swiss mix.

Another consequence is the importance of the assumption made for the electricity substitution. In the present case, the Swiss mix including the imports is substituted. This is however controversial and the results might be sensitive to this assumption, especially if an electricity mix containing a higher share of fossil resources is substituted.

\section{Conclusions}

This paper has presented a methodology to systematically integrate LCA in thermo-economic process models for the conceptual design of energy conversion systems. Formulating the LCI as a function of the design variables of the thermo-economic model and using a multi-objective optimization algorithm allows for considering the environmental performance calculated by LCIA together with the thermo-economic indicators as objectives functions in the process optimization at an early stage of the process synthesis.

The developed methodology has been demonstrated for the thermochemical cogeneration of SNG and power from lignocellulosic biomass. The results highlight the importance of the process design and integration on the environmental impacts calculated with the LCA. The effect of the increase in efficiency due to process integration leads to a particularly high impact reduction when compared to a conventional design that does not consider such aspects.

The application of a multi-objective optimization has allowed for calculating and analyzing the trade-offs between environmental, economic and thermodynamic objectives. The paper has thereby emphazised that special care needs to be taken in the choice of the functional unit and the objective functions of polygeneration systems. Although convenient in single product systems, considering the quantity, impact and cost of the product is not a valid assumption anymore since the real function of such systems is to convert a limited (renewable) resource into useful services. The results demonstrate that the method is suitable to identify optimal process configurations from an environomic point of view in the decision-making procedure. The choice of the environmental objective function in the optimization is particularly important since it influences the optimal process configuration for a given economic performance. In this regard, the integration of environmental impacts is likely to have an important influence on the engineering decisions linked with process design.

An important outcome of the analysis is the non-correspondance of the thermodynamic optimum with the environmental optimums. The energy service substitution and therefore the increase in energy efficiency are key points for the reduction of environmental impacts. However, the thermodynamic and environmental objectives are not strictly correlated one with the other, especially in case of a process producing multiple energy services. Subsequently, this confirms the need for integrating the environmental dimension in the optimization procedure as a separate 
objective.

The results of the multi-objective optimization highlight the importance of the impact caused by the logistics, the auxiliary materials and the off-site emissions associated with the process operation which are usually not accounted in the process design considering only thermo-economic objectives. It is therefore important to create a systematic functional link between process design decisions and indirect emissions, which can be addressed with this method but not with a conventional approach. The method allows one to really calculate the environmental impact of a given project rather than deducing this impact from a process design realized for another purpose. In this regard, the mutual exchange of information between the field of LCA and process design is beneficial for both communities. From the point of view of the LCA, the combined method allows for working with realistic and consistent data and conducting a detailed study on the variations in environmental impacts for the different possible evolutions and future generation of the technology. From the point of view of the process design, considering the environmental impact at an early stage of design allows the engineers to efficiently propose pertinent impact mitigation measures and modifications in the process design.

Applied here in the context of biofuel production, the method is also well suited for other technologies used in the field of energy conversion, especially those involving renewable energy sources for which the contribution of off-site emissions might be important. In particular, its extension to the analysis of biorefinery concepts would be of interest. The LCA coupled with process design and integration is the appropriate method to systematically integrate the environmental impact assessment in process design.

\section{References}

Alexander, B., Barton, G., Petrie, J., Romagnoli, J., 2000. Process synthesis and optimisation tools for environmental design: methodology and structure. Computers \& Chemical Engineering $24,1195-1200$.

Alvarado-Morales, M., Terra, J., Gernaey, K., Woodley, J., Gani, R., 2009. Biorefining: Computer aided tools for sustainable design and analysis of bioethanol production. Chemical Engineering Design and Research 87, 1171-1183.

Azapagic, A., Clift, R., 1999. The application of life cycle assessment to process optimization. Computers \& Chemical Engineering 23, 1509-1526.

Bernier, E., Maréchal, F., Samson, R., 2010. Multi-objective design optimisation of a natural gas-combined cycle with carbon dioxide capture in a life cycle perspective. Energy 35, 11211128 .

Brand, G., Braunschweig, A., Scheidegger, A., Schwank, O., 1998. Bewertung in Oekobilanzen mit der Methode des oekologischen Knappheit Oekofaktoren 1997. Tech. rep., Swiss Federal Office of Environment, Bern, Switzerland.

Classen, M., Althaus, H.-J., Blaser, S., Tuchschmid, M., Jungbluth, N., Emmenegger, M. F., 2007. Life Cycle Inventories of Metals, ecoinvent report No 10. Tech. rep., ecoinvent center, CH-8600 Dübendorf, Switzerland.

Dones, R., Bauer, C., Bolliger, R., Burger, B., Heck, T., Röder, A., Emmenegger, M. F., Frischknecht, R., Jungbluth, N., Tuchschmid, M., 2007. Sachbilanzen von Energiesystemen, ecoinvent report No 6. Tech. rep., ecoinvent center, CH-8600 Dübendorf, Switzerland.

Felder, R., 2004. Ecological Impact of the Use of Methane from Wood Gasification, Project Ecogas, Internal Report. Tech. rep., Paul Scherrer Institute (PSI), CH-5232 Villigen, Switzerland. 
Felder, R., Dones, R., 2007. Evaluation of ecological impacts of synthetic natural gas from wood used in current heating and car systems. Biomass and bioenergy 31, 403-415.

Frischknecht, R., Jungbluth, N., 2007. Overview and Methodology, ecoinvent report No 1. Tech. rep., ecoinvent center, CH-8600 Dübendorf, Switzerland.

Frischknecht, R., Jungbluth, N., Althaus, H.-J., Doka, G., Dones, R., Heck, T., Hellweg, S., Hischier, R., Nemecek, T., Rebitzer, G., Spielmann, M., 2005. The ecoinvent database: Overview and methodological framework. International Journal of Life Cycle Assessment 10, 3-9.

Gassner, M., 2010. Process design methodology for thermochemical production of fuels from biomass. Application to the production of Synthetic Natural Gas from lignocellulosic resources. Ph.D. thesis, EPFL.

Gassner, M., Maréchal, F., 2009. Combined mass and energy integration in process design at the example of membrane-based gas separation systems. submitted upon invitation for the special edition of Computers and Chemical Engineering dedicated to the PSE conference 2009.

Gassner, M., Maréchal, F., 2009a. Methodology for the optimal thermo-economic, multi-objective design of thermochemical fuel production from biomass. Computers \& Chemical Engineering 33, 769-781.

Gassner, M., Maréchal, F., 2009b. Thermo-economic process model for thermochemical production of Synthetic Natural Gas (SNG) from lignocellulosic biomass. Biomass and bioenergy 33, $1587-1604$.

Gebreslassie, B., Guillén-Gosálbez, G., Jiménez, L., Boer, D., 2009. Design of environmentally conscious absorption cooling systems via multi-objective optimization and life cycle assessment. Applied Energy 86, 1712-1722.

Gerber, L., Gassner, M., Maréchal, F., 2010. Environomic optimization of SNG production from lignocellulosic biomass using Life Cycle Assessment. In: Proceedings of the 23rd International Conference on Efficiency, Cost, Optimization, Simulation and Environmental Impact of Energy Systems. pp. 441-448.

Goedkoop, M., Spriensma, R., 2000. The Eco-Indicator 99: A damage oriented method for life cycle impact assessment. Tech. rep., PRé Consultants, Amersfoort, The Netherlands.

Grossmann, I., Guillén-Gosálbez, G., 2010. Scope for the application of mathematical programming techniques in the synthesis and planning of sustainable processes. Computers \& Chemical Engineering 34, 1365-1376.

Guillén-Gosálbez, G., Caballero, J., Jiménez, L., 2008. Application of Life Cycle Assessment to the Structural Optimization of Process Flowsheets. Industrial and Engineering Chemistry Research 47, 777-789.

Guillén-Gosálbez, G., Grossmann, I., 2010. A global optimization strategy for the environmentally conscious design of chemical supply chains under uncertainty in the damage assessment model. Computers \& Chemical Engineering 34, 42-58.

Hischier, R., 2007. Life Cycle Inventories of Packaging and Graphical Papers. Tech. rep., ecoinvent center, CH-8600 Dübendorf, Switzerland.

Hugo, A., Pistikopoulos, E., 2005. Environmentally conscious long-range planning and design of supply chain networks. Journal of Cleaner Production 13, 1471-1491. 
Hässig, W., Primas, A., 2007. Life Cycle Inventories of Comfort Ventilation in Dwellings, ecoinvent report No 25. Tech. rep., ecoinvent center, CH-8600 Dübendorf, Switzerland.

ISO, 2006a. Environmental management - Life Cycle Assessment - Principles and framework. International Standard, ISO 14'040.

ISO, 2006b. Environmental management - Life Cycle Assessment - Requirements and guidelines. International Standard, ISO 14'044.

Keoleian, G., 2003. The application of life cycle assessment to design. Journal of Cleaner Production 1, 143-149.

Kirschner, M. J., 2009. Oxygen. In: Ullmann's encyclopedia of industrial chemistry, 7th Edition. Wiley-VCH.

Kniel, G., Delmarco, K., Petrie, J., 1996. Life Cycle Assessment Applied to Process Design: Environmental and Economic Analysis and Optimization of a Nitric Acid Plant. Environmental Progress 15, 221-228.

Li, H., Maréchal, F., Burer, M., Favrat, D., 2006. Multi-objective optimization of an advanced combined cycle power plant including CO2 separation systems. Energy 31, 3117-3134.

Luterbacher, J. S., Fröling, M., Vogel, F., Maréchal, F., Tester, J. W., 2009. Hydrothermal gasification of waste biomass: Process design and life cycle assessment. Environmental Science and Technology 43, 1578-1583.

Martinez, P., Eliceche, A., 2009. Minimization of life cycle CO2 emissions in steam and power plants. Clean Technologies and Environmental Policy 11, 49-57.

Molyneaux, A., Leyland, G., Favrat, D., 2010. Environomic multi-objective optimisation of a district heating network considering centralized and decentralized heat pumps. Energy 35, $751-758$.

Papandreou, V., Shang, Z., 2008. A multi-criteria optimisation approach for the design of sustainable utility systems. Computers \& Chemical Engineering 32, 1589-1602.

Stefanis, S., Livingston, A., Pistikopoulos, E., 1995. Minimizing the environmental impact of process plants: a process systems methodology. Computers \& Chemical Engineering 19 (SUPPL.1), 39-44.

Steiner, R., Frischknecht, R., 2007. Metals Processing and Compressed Air Supply, ecoinvent report No 23. Tech. rep., ecoinvent center, CH-8600 Dübendorf, Switzerland.

Stucki, S., Schildhauer, T., Biollaz, S., Rüdisühli, M., Vogel, F., Schubert, M., Mazzotti, M., Baciocchi, R., Paredes, G., Maréchal, F., Gassner, M., Zah, R., Steubing, B., Thees, O., Markard, J., Wirth, S., 2010. 2nd Generation Biogas. New Pathways to Efficient Use of Biomass. Final Report. Tech. rep., Competence Center Energy and Mobility.

Tock, L., Gassner, M., Maréchal, F., 2010a. Thermo-economic Evaluation of the Thermochemical Production of Liquid Fuels from Biomass. In: Proceedings of the 23rd International Conference on Efficiency, Cost, Optimization, Simulation and Environmental Impact of Energy Systems. pp. 190-197.

Tock, L., Gassner, M., Maréchal, F., 2010b. Thermochemical production liquid fuels from biomass: Thermo-economic modeling, process design and process integration analysis. Biomass and Bioenergy 34, $1838-1854$. 
Turton, R., Bailie, R., Whiting, W., Shaiewitz, J., 1998. Analysis, synthesis and design of chemical processes. Prentic Hall, New Jersey.

Ulrich, G.-D., 1996. A guide to chemical engineering process design and economics. Wiley, New York.

von Blottnitz, H., Curran, M. A., 2007. A review of assessments conducted on bio-ethanol as a transportation fuel from a net energy, greenhouse gas, and environmental life cycle perspective. Journal of Cleaner Production 15, 607-619.

Zah, R., Böni, H., Gauch, M., Hischier, R., Lehmann, M., Wäger, P., 2007. Oekobilanz von Energieprodukten: Oekologisches Bewertung von Biotreibstoffen. Tech. rep., Swiss Federal Laboratories for Materials Testing and Research (Empa), CH-9014 St. Gallen, Switzerland.

\section{Appendix}

\section{A Impact scaling method for process equipment}

\section{A.1 General methodology}

Prior to establishing the methodology for the impact scaling of process equipment, it is necessary to define the subsystems limits to be considered for the LCA of the process equipment. These limits are displayed in Figure 13. Recycling is not included, since the flows are assumed to leave the system.

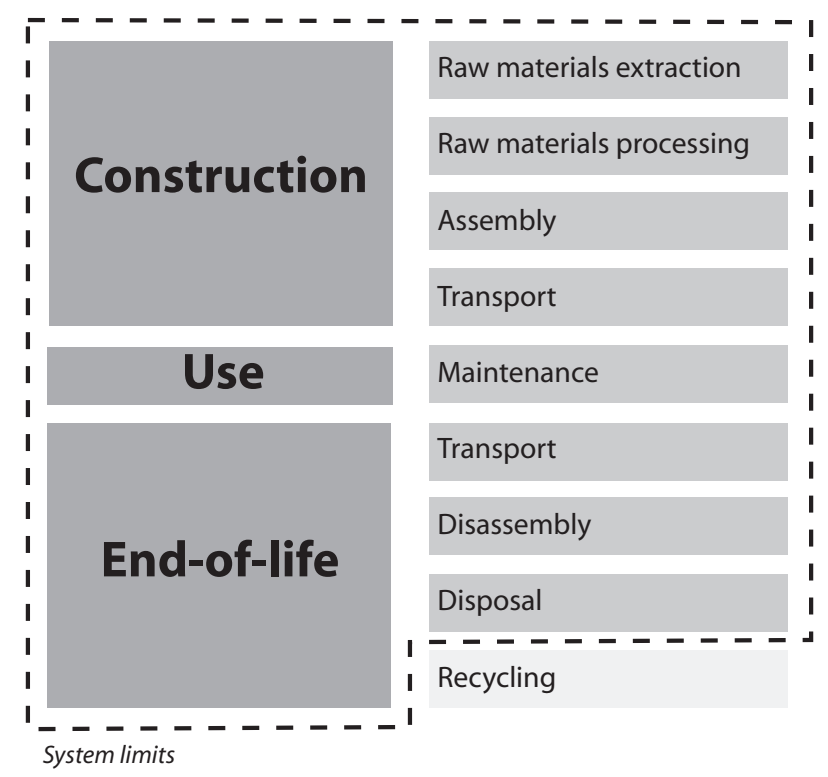

Figure 13: Systems limits for LCA of process equipment

The calculation of the impacts for the production phase, excluding the transportation of the manufactured process equipment to its place of use has been outlined in Equation (6). The impact scaling laws definition concerns first the determination of the functional parameter $A$, that represents the size of the type of process equipment. Then, the exponents $\mathbf{k}_{\mathbf{j}, \mathbf{i}}$ of Equation (6) have to be estimated. This estimation is however subject to the availability of data from the LCI datasets. Indeed, the direct determination of the exponents $\mathbf{k}_{\mathbf{j}, \mathbf{i}}$ for each emission of the LCI involves that two or more reference datasets at different sizes for the same type of process equipment are available from the LCI database. However, most of the time LCI databases at 
the present time do not contain enough information on the production of process equipment. Therefore, other ways of estimating the exponents $\mathbf{k}_{\mathbf{j}, \mathbf{i}}$ have been developed in the case where not enough data are available from the LCI database.

Three different cases can be distinguished, and for each case a method is defined to establish the impact scaling law from the process equipment:

- Case 1: at least two datasets are available in the LCI database for the type of process equipment. In this case, the exponents $\mathbf{k}_{\mathbf{j}, \mathbf{i}}$ can directly be determined for each LCI emission, transforming Equation (6) into:

$$
\mathbf{k}_{\mathbf{j}, \mathbf{i}}=\frac{\log \mathbf{E}_{\mathbf{j}_{1}, \mathbf{i}}-\log \mathbf{E}_{\mathbf{j}_{2}, \mathbf{i}}}{\log \mathbf{A}_{\mathbf{j}_{1}}-\log \mathbf{A}_{\mathbf{j}_{2}}}-\log \mathbf{c}_{\mathbf{j}}^{*}
$$

where $\mathbf{E}_{\mathbf{j}_{1}, \mathbf{i}}$ is the emission $i$ for the reference dataset with the value $\mathbf{A}_{\mathbf{j}_{1}}$ for the functional parameter linked to the size, and $\mathbf{E}_{\mathbf{j}_{\mathbf{2}}, \mathbf{i}}$ is the emission $i$ for the reference dataset with the value $\mathbf{A}_{\mathbf{j}_{\mathbf{2}}}$ for the functional parameter, and $\mathbf{c}_{\mathbf{j}}^{*}$ is a constant related to the correction factor $\mathbf{c}_{\mathbf{j}}$. If more than two datasets are available, a linear regression is performed on the following equation:

$$
\log \left(\frac{\mathbf{E}_{\mathbf{j}, \mathbf{i}}}{\mathbf{E}_{\mathbf{j}_{\text {ref }}}}\right)=\mathbf{k}_{\mathbf{j}, \mathbf{i}} \cdot \log \frac{\mathbf{A}_{\mathbf{j}}}{\mathbf{A}_{\mathbf{j}, \mathbf{r e f}}}+\log \mathbf{c}_{\mathbf{j}}
$$

- Case 2: Only one dataset is available in the LCI database for the type of process equipment. In this case, the exponents $\mathbf{k}_{\mathbf{j}, \mathbf{i}}$ can not be directly determined for each LCI emission. By similarity between the economic and the environmental scaling laws, it is then assumed that the ratio of the costs is equal to the ratio of the emissions at two different sizes. Therefore, the emission exponents $\mathbf{k}_{\mathbf{j}, \mathbf{i}}$ of the LCI emissions are assumed to be equal to the one for the investment cost scaling, and the impact scaling law becomes:

$$
\frac{E_{j, i}}{\mathbf{E}_{\mathbf{j}, \mathbf{i}, \text { ref }}}=\frac{C_{j}}{\mathbf{C}_{\mathbf{j}, \text { ref }}}
$$

where $E_{j, i}$ is the scaled emission of the elementary flow $i, \mathbf{E}_{\mathbf{j}, \mathbf{i}, \mathbf{r e f}}$ is the reference emission of the LCI dataset, $C_{j}$ is the scaled investment cost, and $\mathbf{C}_{\mathbf{j}, \text { ref }}$ is the reference investment cost. $C_{j}$ and $\mathbf{C}_{\mathbf{j}, \text { ref }}$ are both calculated using the well-established correlations from Ulrich (1996) and Turton et al. (1998). As shown by the example of the compressor in Figure $5(\mathrm{~b})$, this approximation is likely to lead to a better estimation of the scaled emissions than linear extrapolation.

- Case 3: No dataset is available in the LCI database for the type of process equipment. In this case, it is necessary to perform the LCA of the process equipment by considering the different materials of construction. Equivalences are then found in the LCI database for these materials. A scaling law has then to be established to calculate the quantity of each one of these materials, using design data at different sizes. The scaled emissions for the considered type of process equipment become:

$$
E_{j, i}=\sum_{u=1}^{n} E_{j, i, u}
$$

where $E_{j, i}$ is the scaled emission of the elementary flow $i, E_{j, i, u}$ is the scaled emission of the elementary flow $i$ from the material $u$ composing the process equipment $j$, and $n$ is the total number of construction materials for the process equipment $j$.

All the three cases were encountered in the definition of the impact scaling laws of the process equipment involved in the SNG production. 
As shown by Figure 13, it is necessary to include not only the production of the process equipment, but also the use phase including maintenance, and the end-of-life phase including disassembly, transportation and disposal.

By analogy with the economic assumptions where maintenance is commonly assumed to represent $5 \%$ of the costs per year (Turton et al. (1998)), maintenance is assumed to represent $5 \%$ of the total impact of the process equipment per year of operation. To account for transportation in the production, the end-of-life phases and the disposal, the mass of process equipment is calculated. It is assumed that the mass follows a similar law to the cost and impact scaling laws:

$$
\frac{m_{j}}{\mathbf{m}_{\mathbf{j}, \text { ref }}}=\left(\frac{A_{j}}{\mathbf{A}_{\mathbf{j}, \text { ref }}}\right)^{\mathbf{k}_{\mathbf{j}, \mathbf{m}}}
$$

where $m_{j}$ is the mass of the process equipment $j$ to be calculated, $\mathbf{m}_{\mathbf{j} \text {,ref }}$ is the mass of a reference process equipment, $A_{j}$ is the functional parameter of the process equipment $j$ and $\mathbf{k}_{\mathbf{j}, \mathbf{m}}$ is an exponent.

The general methodology for the definition of impact scaling laws is summarized step-by-step in Figure 4.

Appendix A.2 to A.8 summarize how these impact scaling laws were established for each type of process equipment with this approach.

\section{A.2 Boiler}

The functional parameter for a boiler is the thermal power in $\mathrm{kW}_{t h}$.

Two datasets with different thermal power are available in the LCI database for an oil boiler at $10 \mathrm{~kW}_{t h}$ and at $100 \mathrm{~kW}_{t h}$ including production, assembly and disposal (Dones et al. (2007)). These datasets are then directly used to determine the exponents $\mathbf{k}_{\mathbf{j}, \mathbf{i}}$ of the impact scaling law from Equation (14).

No correction factor $\mathbf{c}_{\mathbf{j}}$ is applied in the case of the boiler, since it is assumed that the steam boiler used in the SNG production is similar to the oil boiler of the LCI database.

The mass of the boiler is calculated by Equation (18) for estimating the impact due to transport. In Dones et al. (2007), masses are given for three different thermal powers of an oil boiler at 10, 100 and $1000 \mathrm{~kW}_{t h}$ and are used to calculate the exponent $\mathbf{k}_{\mathbf{j}, \mathbf{m}}=0.80$.

\section{A.3 Compressor}

The functional parameter for a compressor is the electrical power in $\mathrm{kW}_{e}$.

Two datasets with different electrical power are available in the LCI database for a screw-type air compressor at $4 \mathrm{~kW}_{e}$ and $300 \mathrm{~kW}_{e}$ including production, assembly and disposal (Steiner and Frischknecht (2007)). These datasets are then directly used to determine the exponents $\mathbf{k}_{\mathbf{j}, \mathbf{i}}$ of the impact scaling law from Equation (14).

In case of the compressor, it is necessary to apply a correction factor $\mathbf{c}_{\mathbf{j}}$. Indeed, the compressor of the LCI datasets is of screw-type, while the ones considered in the SNG production are of centrifugal or axial type. Since the costs of an axial or centrifugal compressor are higher than for a screw-type compressor (Ulrich (1996)), a similar effect for the impact is assumed, following the analogy for emission scaling. Therefore, the correction factors corresponding to the electrical power of the two datasets are also applied to the LCI of the two datasets prior to calculating the exponents $\mathbf{k}_{\mathbf{j}, \mathbf{i}}$.

The mass of the compressor for estimating the impact due to transport is calculated by Equation (18). In Steiner and Frischknecht (2007), masses are given for the two different electrical powers of the screw-type compressor. The same correction factors from Ulrich (1996) were applied to the masses to estimate the exponent $\mathbf{k}_{\mathbf{j}, \mathbf{m}}=0.94$ for an axial or a centrifugal compressor. 


\section{A.4 Filter}

The functional parameter for a filter is the volumetric flow rate in $\mathrm{Nm}^{3} / \mathrm{s}$.

Only one dataset is available in the LCI database for a central-unit filter at $600 \mathrm{~m}^{3} / \mathrm{h}$ including production, assembly and disposal (Hässig and Primas (2007)). Though the application field of this dataset is a family house, the technology of bag filters is similar to the one used in the filter of the SNG production, and it is assumed that this dataset can be used. Since only one reference size dataset is available, it is not possible to directly calculate the exponents $\mathbf{k}_{\mathbf{j}, \mathbf{i}}$ of Equation (6). Therefore, Equation (16) is used, following the costs scaling law from Ulrich (1996) for bag filters.

No correction factor $\mathbf{c}_{\mathbf{j}}$ is applied in the case of the bag filter.

A similar approach to the one used for emission scaling was used to estimate the mass of the filters, since a reference mass is available from Hässig and Primas (2007).

\section{A.5 Heat exchanger}

The functional parameter for a heat exchanger is the exchange area in $\mathrm{m}^{2}$.

Since detailed design data for a tube and shell heat exchanger are available at different sizes and that no datasets are available at different sizes from the LCI database, the design data are used to directly calculate the quantities of materials. The heat exchanger is composed by two different materials: stainless steel for the tubes and the shell, and unalloyed steel for the other parts of the heat exchanger. Equivalences are available for the production of these two materials in the LCI database. For each material, a mathematical expression is developed to scale its quantity in function of the exchange area, based on the available design data. The amount of stainless steel was found to follow a linear scaling law of the type:

$$
\frac{m_{j}}{\mathbf{m}_{\mathbf{j}, \text { ref }}}=\frac{A_{j}}{\mathbf{A}_{\mathbf{j}, \text { ref }}}
$$

where $m_{j}$ is the mass of stainless steel to be calculated $\mathbf{m}_{\mathbf{j}, \text { ref }}$ the one of a reference heat exchanger and $A_{j}$ is the exchange area. The amount of unalloyed steel was found to follow a similar law to Equation (18). The exponent $\mathbf{k}_{\mathbf{j}, \mathbf{m}}$ was estimated to 0.59. These masses are then used to calculate the LCI of the associated equivalent materials, with Equation 17.

For the cost estimation of a heat exchanger, it is also necessary to apply a correction factor for the pressure (Turton et al. (1998)). Following the analogy between cost and impact estimation, the correction factor $\mathbf{c}_{\mathbf{j}}$ for the pressure is also applied to the impact scaling, and the correlations from Turton et al. (1998) are used to correct the emissions of the LCI before LCIA.

The masses are also used to calculate the impacts due to transportation and disposal. For the disposal, it is assumed that $98 \%$ of the steel could be recycled. This is the assumption made by Felder and Dones (2007) for the recycling of the metal catalysts. The remaining $2 \%$ are assumed to be disposed in sanitary landfill as inert material. It is assumed that the impacts from the assembly and the disassembly can be neglected.

\section{A.6 Membrane}

The functional parameter for a membrane is the exchange area in $\mathrm{m}^{2}$.

There is no specific dataset available in the LCI database for a membrane. However, since this one is made from polymer, it is assumed that another equivalence for polymer in a sheet form could be taken. Then, the mass of polymer is calculated by the following equation:

$$
m_{j}=\rho_{\mathbf{j}} \cdot A_{j} \cdot \delta_{j}
$$

where $m_{j}$ is the mass of the membrane, $\rho_{\mathbf{j}}$ is the density of the polymer, $A_{j}$ is the exchange area of the membrane, and $\delta_{j}$ is the membrane thickness, assumed as constant in the thermo-economic model. 
The impacts due to transport and disposal are also calculated using the quantity of polymer. For the disposal, it is assumed that the membranes are incinerated.

\section{A.7 Pump}

The functional parameter for a pump is the electrical power in $\mathrm{kW}_{e}$.

Only one dataset is available for a pump at $40 \mathrm{~W}$ in the LCI database including production, assembly and disposal (Dones et al. (2007)). Since only one reference dataset is available, it is not possible to directly calculate the exponents $\mathbf{k}_{\mathbf{j}, \mathbf{i}}$ with Equation (14). Therefore, Equation (16) was used, following the cost scaling correlation from Turton et al. (1998) for centrifugal pumps.

For the cost estimation of a pump, it is also necessary to apply a correction factor for the pressure (Turton et al. (1998)). Following the analogy between cost and impact estimation, the correction factor $\mathbf{c}_{\mathbf{j}}$ for the pressure is also applied to the impact scaling, and the correlations from Turton et al. (1998) are used to correct the emissions of the LCI before LCIA.

For the mass, a similar approach to the one used for the emission scaling is used, since a reference mass is available from Dones et al. (2007).

\section{A.8 Reactor}

The functional parameter for a reactor is the volume in $\mathrm{m}^{3}$.

Since no dataset is available from the LCI database for a reactor, it is necessary to use design data. The reactor is therefore assimilated to a cylinder made of stainless steel. An equivalence for stainless steel is available in the LCI database, and the amount of stainless steel is calculated by:

$$
m_{j}=\rho_{\mathbf{j}} \cdot \delta_{j} \cdot \pi \cdot\left(d_{j} \cdot h_{j}+2 \cdot\left(\frac{d_{j}}{2}\right)^{2}\right)
$$

where $\mathrm{m}_{j}$ is the mass of the reactor, assumed to be fully made of stainless steel, $\rho_{\mathbf{j}}$ is the density of stainless steel, $\delta_{j}$ is the thickness of the reactor wall, $d_{j}$ is the diameter, and $h_{j}$ is the height of the reactor.

For the cost estimation of a reactor, it is also necessary to apply a correction factor for the pressure (Turton et al. (1998)). Following the analogy between costs and impacts estimation, the correction factor $\mathbf{c}$ for the pressure is also applied to the impact scaling, and the correlations from Turton et al. (1998) are used to correct the emissions of the LCI before LCIA.

The mass of stainless steel is also used to calculate the impacts due to transport and disposal. For the disposal, it is assumed that $98 \%$ of the steel could be recycled, and therefore are leaving the system. This is the assumption made by Felder and Dones (2007) for the recycling of the metal catalysts. The remaining $2 \%$ are assumed to be disposed in the sanitary landfill as inert material. It is assumed that the impacts from the assembly and the disassembly can be neglected. 